\title{
GANANCIAS ILÍCITAS DE LA DELINCUENCIA TRANSNACIONAL E INSTRUMENTOS PENALES PARA DISUADIRLA ${ }^{1}$
}

\author{
Clara Moya Guillem* \\ Patricia Tapia Ballesteros**
}

Resumen: El lucro constituye la motivación principal de la delincuencia transnacional. Por consiguiente, si se pretende combatir, debería perseguirse dicho incentivo. Para ello resultan de utilidad tres institutos de la Parte general del Derecho penal español que afectan a las ganancias derivadas del delito: la responsabilidad civil,

Recibido: enero 2021. Aceptado: mayo 2021

* Profesora Ayudante Doctora (acred. Profesora Contratada Doctora). ORCID: 0000-0002-1791-8323. Área de Derecho penal. Departamento de Derecho internacional público y Derecho penal. Universidad de Alicante. Email: clara.mg@ua.es

** Profesora Titular. ORCID: 0000-0001-5234-7469. Área de Derecho penal. Departamento de Derecho penal e Historia y Teoría del Derecho. Universidad de Valladolid. Email: patricia.tapia@uva.es

1 La realización de este trabajo se enmarca en el proyecto de investigación "Ganancias ilícitas y Derecho penal" financiado por el Ministerio de Ciencia, Innovación y Universidades (RTI2018-094287-B-I00) y dirigido por la profesora Luz María Puente Aba. 
el decomiso de ganancias y la pena de multa proporcional. Pero, sorprendentemente, no suelen emplearse en relación con los delitos transnacionales regulados en el Código penal español. El objetivo de este trabajo es, precisamente, examinar las consecuencias jurídico-penales actualmente previstas en los delitos transnacionales (en particular, en aquellos que reprimen los tráficos de drogas, armas y personas), así como su aplicación en la jurisprudencia más reciente. De este modo, se podrá determinar si resultan eficaces en términos de prevención general o si resultaría más eficaz el empleo de otras herramientas en esta dirección.

Palabras clave: ganancias ilícitas, delincuencia transnacional, tráficos ilícitos, pena de multa, decomiso.

\section{ILLICIT PROFITS FROM TRANSNATIONAL CRIME AND \\ CRIMINAL INSTRUMENTS TO DETER IT}

Abstract: Profit is the main motivation for transnational crime. Consequently, if fight is to be sought, such an incentive should be pursued. For this, three legal principles of the General Part of Spanish Criminal Law that affect the profits derived from crime are useful: civil liability, the confiscation of profits and the penalty of a proportional fine. But, surprisingly, they are not usually used in relation to transnational crimes regulated in the Spanish Criminal Code. The aim of this paper is precisely to examine the legal-criminal consequences currently provided for in transnational crimes (in particular, those related to drug, arms and human trafficking), as well as their application in the most recent jurisprudence. In this way, it will be possible to determine if they are effective in terms of general prevention or if the use of other instruments would be more effective.

Keywords: illicit profits, transnational crime, illicit trafficking, fine, confiscation.

\section{La delincuencia transnacional. Especial referencia a los mercados ilícitos más lucrativos}

La Convención de las Naciones Unidas contra la Delincuencia Organizada Transnacional, aprobada mediante la 
Resolución 55/25 de la Asamblea General, de 15 de noviembre de 2000 (en adelante, "Convención de Palermo"), es el instrumento normativo internacional de referencia en materia de criminalidad organizada transnacional. Sin embargo, no puede obviarse que años antes de su aprobación las $\mathrm{Na}$ ciones Unidas publicaron la Convención contra el Tráfico Ilícito de Estupefacientes y Sustancias Sicotrópicas, mediante la Resolución 1988/8 del Consejo Económico y Social, de 20 de diciembre de 1988, cuya influencia en el contexto del crimen organizado transnacional resulta, igualmente, indiscutible ${ }^{2}$.

Un intenso debate en torno a la delincuencia organizada protagonizó el discurso académico y político en los años noventa, alentado por posturas contrapuestas sobre la existencia y gravedad de este fenómeno difícilmente abarcable en una definición consensuada ${ }^{3}$. El inicio del presente milenio trajo el consenso sobre la definición desde el ámbito internacional basada en un concepto claro desde el punto de vista criminológico. Pero este consenso no se ha trasladado al terreno del marco represivo penal nacional puesto que el traspaso es complejo aunque imprescindible para proceder a mediciones a través de datos procedentes de fuentes oficiales ${ }^{4}$.

2 La Convención de Naciones Unidas contra el Tráfico Ilícito de Estupefacientes y Sustancias Sicotrópicas establece en su artículo 2 que «el propósito de la presente Convención es promover la cooperación entre las Partes a fin de que puedan hacer frente con mayor eficacia a los diversos aspectos del tráfico ilícito de estupefacientes y sustancias sicotrópicas que tengan una dimensión internacional».

3 De hecho, todavía en la actualidad existen autores que lo cuestionan. Véase, al respecto, QUINTERO OLIVARES, G.: "La globalización y el Derecho penal: un cajón de sastre conceptual”, en GALÁN MUÑOZ, A. (Coord.), Globalización y lucha contra las nuevas formas de criminalidad transnacional, Valencia, 2019, p. 19.

4 Sobre dicho concepto, resulta interesante la explicación que contiene el documento "La Lucha contra el Crimen contra el crimen organizado en la Unión Europea" del Centro Superior de Estudios de la Defensa Nacional (2012), disponible en: https://publicaciones.defensa.gob.es/lalucha-contra-el-crimen-organizado-en-la-union-europea.html (última consulta: 10/01/2021). 
En efecto, en la Convención de Palermo se entiende por "grupo delictivo organizado" "un grupo estructurado de tres o más personas que exista durante cierto tiempo y que actúe concertadamente con el propósito de cometer uno o más delitos graves o delitos tipificados con arreglo a la presente Convención con miras a obtener, directa o indirectamente, un beneficio económico u otro beneficio de orden material» (art. 2). De este modo, se adopta una definición de "grupo delictivo organizado" con las siguientes exigencias criminológicas: a) unión de tres o más personas, b) con cierta permanencia en el tiempo, c) que actúe concertadamente, d) para cometer delitos graves o los tipificados en la convención, e) con la finalidad de beneficio económico. Estos son los rasgos que, según las principales normas aprobadas en este ámbito, caracterizan a la delincuencia organizada ${ }^{5}$.

5 La Decisión Marco 2008/841/JAI del Consejo, de 24 de octubre de 2008, relativa a la lucha contra la delincuencia organizada ofrece pocas innovaciones al respecto. Sobre esta norma europea, véase RUIZ DÍAZ, L.J.: "Diez años de la adopción de la Decisión marco 2008/841/JAI, del Consejo relativa a la lucha contra la delincuencia organizada. Luces y sombras de un legado más que dudoso", en Revista de Derecho comunitario europeo, $\mathrm{n}^{\circ}$ 61, 2018, p. 1098. El Documento 6204/2/97 de Europol, en esta misma línea, ya estableció una década antes los siguientes indicadores estadísticos con la finalidad de delimitar la criminalidad organizada: 1) colaboración de más de dos personas, 2) reparto específico de tareas, 3) actuación prolongada o indefinida en el tiempo, 4) uso de algún tipo de disciplina o control interno, 5) comisión de delitos graves, 6) extensión de la actividad al ámbito internacional, 7) uso de la violencia, 8) uso de estructuras económicas o comerciales, 9) implicación en el blanqueo de capitales, 10) uso de influencia o corrupción, y 11) búsqueda de beneficios o poder. Según esta agencia, se requieren 6 indicadores para ser grupo organizado: obligatoriamente el 1, el 3 , el 5 y el 11. De igual modo, por lo que se refiere, en particular, a España, la Orden PCI/161/2019, de 21 de febrero, por la que se publica el Acuerdo del Consejo de Seguridad Nacional, por el que se aprueba la Estrategia Nacional contra el Crimen Organizado y la Delincuencia Grave establece una serie de características que configuran el concepto de crimen organizado, y que, principalmente, son: a) finalidad esencialmente económica, b) implicación en actividades ilícitas complementadas con actividades legales, c) asociación de una pluralidad de personas, 
Pero dicha Convención de Palermo sólo resulta de aplicación cuando esa delincuencia organizada es, además, transnacional ${ }^{6}$. Este rasgo se da, según la norma, si concurre alguna de las siguientes circunstancias en el delito: «a) se comete en más de un Estado; b) se comete dentro de un solo Estado, pero una parte sustancial de su preparación, planificación, dirección o control se realiza en otro Estado; c) se comete dentro de un solo Estado, pero entraña la participación

d) carácter de continuidad en el tiempo, e) empleo de medidas de seguridad, f) adaptabilidad, g) transnacionalidad, h) provoca efectos indeseables en el ciudadano, la sociedad y en los Estados con importante potencial desestabilizador, e i) uso de influencia o corrupción. Y, entre la doctrina, OLASOLO ALONSO añade que para poder desplegar sus actividades a lo largo del tiempo estas organizaciones requieren de varias características. En primer lugar, tratan de presentarse como empresas económicas lícitas. En segundo lugar, requieren de una conexión estructural con los poderes públicos y privados del ámbito en el que operan, lo que hace que la corrupción juegue un papel medular en sus actividades. En tercer lugar, actúan a través de redes, de manera que sus miembros pueden confiar en un tejido de puntos de contacto en una multiplicidad de Estados con el que desarrollar sus actividades de forma segura. En cuarto lugar, cuentan con una alta capacidad de transformación, que se apoya en gran medida en el carácter etéreo de sus amplias redes de puntos de contacto. Finalmente, sostienen su acción recurriendo a la amenaza y al ejercicio de la violencia. Al respecto, OLASOLO ALONSO, H.: “¿Se debe recurrir a los mecanismos de respuesta del Derecho internacional penal para hacer frente a los delitos transnacionales?", en PÉREZ CEPEDA, A.I. (Dir.), Politica criminal ante el reto de la delincuencia transnacional, Valencia, 2016, p. 131.

6 Cabe apuntar, en todo caso, como afirma ZÚÑIGA RODRÍGUEZ, que la delincuencia transnacional siempre será organizada. Por ejemplo, los tráficos ilícitos internacionales comportan relaciones en redes de colaboración para la ejecución de los mismos, en lo que respecta a la obtención del bien ilícito, los medios de transporte, la compra y venta de los objetos ilícitos, provisión de bienes para el mantenimiento de la estructura criminal, etc., sin olvidar que en muchos casos se requiere además colaboración de operadores policiales y judiciales, contratación de profesionales especializados, etc. En suma, este tipo de delincuencia transnacional requiere una organización. Al respecto, ZÚÑIGA RODRÍGUEZ, L.: "El concepto de criminalidad organizada transnacional: problemas y propuestas", en PÉREZ CEPEDA, A.I. (Dir.), Politica criminal ante el reto de la delincuencia transnacional, ob. cit., p. 182. 
de un grupo delictivo organizado que realiza actividades delictivas en más de un Estado; o d) se comete en un solo Estado, pero tiene efectos sustanciales en otro Estado» (art. 3).

Este instrumento normativo internacional, sin embargo, se aplica a la prevención, la investigación y el enjuiciamiento, por un lado, de todo delito de participación en un grupo delictivo organizado, blanqueo de capitales, corrupción y obstrucción a la justicia; y, por otro lado, de los delitos punibles con una privación de libertad máxima de al menos cuatro años, en este caso sí, con la condición de que se trate de delitos de carácter transnacional y entrañen la participación de un grupo delictivo organizado (art. 3) ${ }^{7}$. De igual modo, la Convención de Palermo resulta de aplicación para la persecución de los siguientes fenómenos criminales: la trata de personas, el tráfico ilícito de migrantes y el tráfico de armas. Esto se debe a que los tres protocolos que la complementan: el Protocolo para prevenir, reprimir y sancionar la trata de personas, especialmente mujeres y niños; el Protocolo contra el tráfico ilícito de migrantes por tierra, mar y aire; y el Protocolo contra la fabricación y el tráfico ilícitos de armas de fuego, sus piezas y componentes y municiones, así lo establecen de manera explícita ${ }^{8}$.

En conclusión, según los principales instrumentos normativos internacionales aprobados en el seno de Naciones Unidas se considera "delincuencia transnacional", específicamente: la participación en un grupo delictivo organizado, el blanqueo de capitales, la corrupción, la obstrucción a

7 Este segundo grupo de delitos se consideran en la Convención de Palermo "delitos graves" (art. 2). Y esta es la misma definición de "delito grave" se facilitó, posteriormente, en la Decisión Marco 2008/841/JAI del Consejo, de 24 de octubre de 2008, relativa a la lucha contra la delincuencia organizada.

8 En los tres protocolos complementarios a la Convención de Palermo se ha insertado la misma fórmula: «los delitos tipificados con arreglo al artículo [...] del presente Protocolo se considerarán tipificados con arreglo a la Convención». 
la justicia, la trata de personas, el tráfico ilegal de migrantes, el tráfico de armas y el tráfico de drogas.

Con todo, a la vista de lo cambiante de la delincuencia transnacional, aunque este listado pueda constituir el punto de partida para acotar los fenómenos que la conforman, debe acudirse a las normas y documentos oficiales nacionales ${ }^{9}$ y supranacionales ${ }^{10}$ más recientes, así como a la doctrina especializada $^{11}$, con la finalidad de confirmar si estos mismos

9 A nivel nacional se ha tenido en cuenta para la delimitación de los fenómenos criminales constitutivos de la delincuencia transnacional la Ley Orgánica 6/1985, de 1 de julio, del Poder Judicial y la Orden PCI/161/2019, de 21 de febrero, por la que se publica el Acuerdo del Consejo de Seguridad Nacional, por el que se aprueba la Estrategia Nacional contra el Crimen Organizado y la Delincuencia Grave.

10 Por lo que se refiere a Europa, son tres los instrumentos normativos tenidos en cuenta para la delimitación de la delincuencia transnacional que se realiza en este trabajo: la Directiva 2016/681, del Parlamento Europeo y del Consejo, de 27 de abril de 2016, relativa a la utilización de datos del registro de nombres de los pasajeros para la prevención, detección, investigación y enjuiciamiento de los delitos de terrorismo y de la delincuencia grave; el artículo 83.1 del Tratado de Funcionamiento de la Unión Europea (versión consolidada 2016); y el artículo 2.1 del Convenio basado en el artículo K.3 del Tratado de la Unión Europea por el que se crea una oficina europea de policía (Convenio Europol), de 26 de julio de 1995. Se han tenido en consideración,, asimismo, el Documento 10415/00 del Consejo de la Unión Europea, de 3 de agosto de 2000, y la Decisión Marco 2002/584/JAI del Consejo, de 13 de junio de 2002, relativa a la orden de detención europea y a los procedimientos de entrega entre Estados miembros.

11 PÉREZ CEPEDA, A.I.: “Existe un sistema penal transnacional?”, en PÉREZ CEPEDA, A.I. (Dir.), Politica criminal ante el reto de la delincuencia transnacional, ob. cit., p. 221, identifica los siguientes: el tráfico de drogas, el tráfico de seres humanos, el tráfico de armas, el mercado de obras de arte y restos arqueológicos, tráfico de vehículos, los delitos cometidos a través de la informática, la falsificación de tarjetas de crédito, los crímenes contra el medio ambiente, el tráfico ilícito de órganos, el blanqueo de capitales y muchos otros delitos graves. Por su parte, se refiere a los clásicos delitos transnacionales (el tráfico de drogas, la trata de seres humanos y el tráfico de armas) QUINTERO OLIVARES, G.: "La globalización y el Derecho penal: un cajón de sastre conceptual", ob. cit., p. 21. 
fenómenos conforman actualmente la denominada "delincuencia transnacional". Si se analizan todas estas fuentes de forma conjunta se detectan hasta siete fenómenos criminales que se consideran criminalidad transnacional por la práctica totalidad de ellos: el tráfico de drogas, la corrupción, el blanqueo de capitales, la trata de seres humanos, el tráfico ilícito de migrantes, el tráfico de armas y la ciberdelincuencia ${ }^{12}$.

Así pues, como se puede observar, la delincuencia transnacional en sentido amplio abarcaría los diversos tráficos ilícitos y la delincuencia económica. Como sostiene OLASOLO ALONSO, la mayoría, sino todos, de los delitos transnacionales consisten en transacciones económicas en mercados prohibidos por la ley, que tienen por objeto la oferta o la demanda de bienes ilícitos (drogas, armas, propiedad cultural, recursos naturales, materiales contaminantes, propiedad intelectual), seres humanos (inmigrantes, mujeres, niños) o servicios para facilitar y organizar dichas transacciones (blanqueo de dinero, corrupción, piratería, delitos cibernéticos y terrorismo $)^{13}$.

12 Debe tenerse en consideración, además, que esta distinción ya no es tan evidente. Actualmente, proliferan los grupos de carácter policriminal (que combinan, por ejemplo, el tráfico de drogas con el tráfico ilícito de migrantes o con la trata de seres humanos). Al respecto, véase el Informe anual de Seguridad Nacional 2019, disponible en: https://www.dsn.gob. es/es/documento/informe-anual-seguridad-nacional-2019, (fecha de acceso: 10/01/2021), p. 41.

13 OLASOLO ALONSO, H.: “Se debe recurrir a los mecanismos de respuesta del Derecho internacional penal para hacer frente a los delitos transnacionales?", ob. cit., p. 119. Este mismo autor aclara que la razón de la prohibición de estos mercados se encuentra generalmente en la entidad de su posible impacto en los Estados que promueven su prohibición. Incluso en relación con el tráfico de personas, el aspecto central de la prohibición se encuentra en la finalidad de explotación o de obtener directa o indirectamente un beneficio financiero u otro beneficio de orden material (art. 3 de los Protocolos adicionales, relativos al tráfico ilícito de migrantes y a la trata de personas), y no en el hecho de ejercer derechos de propiedad sobre los seres humanos con los que se trafica. 
No obstante, este trabajo se va a centrar en el examen de los tráficos de drogas, armas y personas ${ }^{14}$, ya que constituyen, como se verá a continuación, los mercados ilícitos más lucrativos que existen en la actualidad. Además, integran cuatro de las diez prioridades para el actual ciclo 2018-2021 detalladas en las Conclusiones del Consejo sobre la determinación de las prioridades de la UE para la lucha contra la delincuencia internacional organizada y grave (Doc. 7704/17) ${ }^{15}$. Los recursos que los criminales emplean tanto para cometer delitos, al reducirse o eliminarse los controles, como para obtener mayores beneficios y transferir los beneficios resultantes de los mismos en actividades de apariencia lícita ${ }^{16}$, tales como la corrupción o el blanqueo de capitales, que son ilícitos donde confluyen las diversas formas de criminalidad transnacional ${ }^{17}$, no serán objeto del trabajo. Estos fenómenos se dejan al margen porque su existencia suele depender de otras formas de criminalidad principales.

14 En adelante, en coherencia con la terminología empleada en los Protocolos adicionales a la Convención de las Naciones Unidas contra la Delincuencia Organizada Transnacional, se emplearán las expresiones "trata de personas" y "tráfico ilícito de migrantes" para hacer referencia a estos fenómenos, aunque no puede desconocerse que existe cierto debate en relación con el uso de los mismos y que entre la doctrina penal española se utilizan con más frecuencia, respectivamente, las expresiones "trata de seres humanos" e "inmigración clandestina".

15 En particular, las prioridades son: la ciberdelincuencia, el tráfico de drogas, la inmigración ilegal, la delincuencia organizada contra la propiedad, la trata de seres humanos, el fraude, el tráfico, la distribución y el uso de armas de fuego, los delitos contra el medio ambiente, las operaciones financieras delictivas y el blanqueo de capitales. Estos tráficos ilícitos son, además, uno de los riesgos globales subrayados por el Global Risks Report 2020 del Word Economic forum, disponible en: https://www.weforum.org/reports/the-global-risks-report-2020 (última consulta: 10/01/2021).

16 PÉREZ CEPEDA, A.I.: “Existe un sistema penal transnacional?”, ob. cit., p. 220.

17 ZÚÑIGA RODRÍGUEZ, L.: "El concepto de criminalidad organizada transnacional: problemas y propuestas", ob. cit., p. 161. 
Sentado lo anterior, la finalidad de esta investigación es valorar si los recursos disponibles en el ordenamiento jurídico-penal español sirven para prevenir este tipo de delincuencia transnacional, teniendo en cuenta que, como han afirmado las instituciones de la Unión Europea, «la motivación principal de la delincuencia organizada transfronteriza, incluida la de carácter mafioso, es la obtención de beneficios financieros $\rangle^{18}$ y que, por ende, si se pretende combatir este fenómeno criminal debería perseguirse el principal incentivo de quienes lo llevan a cabo: el lucro. Para esta labor son tres las instituciones de la Parte general del Derecho penal español que podrían ser de utilidad: la pena de multa proporcional, el decomiso de ganancias y la responsabilidad civil derivada del delito ${ }^{19}$.

En las siguientes páginas se va a analizar cómo se regulan estos tres instrumentos para las personas físicas en los delitos transnacionales de tráfico de drogas, tráfico de armas, tráfico ilícito de migrantes y trata de seres humanos, así como su aplicación por parte de la jurisprudencia a través del análisis de las sentencias condenatorias dictadas en el año 2019. Sin embargo, de forma previa, por un lado, se dará cuenta de las estimaciones publicadas acerca de las ganancias ilícitas

18 Así lo afirma la Directiva 2014/42/UE, del Parlamento europeo y del Consejo, de 3 de abril de 2014, sobre el embargo y el decomiso de los instrumentos y del producto del delito en la Unión Europea.

19 También podrían tener esta misma utilidad, por ejemplo, el delito fiscal o el de blanqueo de capitales, que se dejan al margen del presente trabajo, que no se refiere a las figuras contempladas en la Parte especial del Derecho penal con esta finalidad. Asimismo, perseguiría directamente el lucro generado por la delincuencia transnacional el delito de enriquecimiento ilícito, pero, como se sabe, actualmente, todavía no se ha previsto en el ordenamiento jurídico-penal español. Véanse, al respecto, BLANCO CORDERO, I.: "El debate en España sobre la necesidad de castigar penalmente el enriquecimiento ilícito de empleados públicos", en Revista electrónica de ciencia penal y criminológica, $\mathrm{n}^{\circ} 19,2017$, pp. 1-35; y DURÁN SILVA, C.: "Las presunciones legales iuris tantum en la figura del decomiso", en Revista General de Derecho Procesal, n 48 , 2019, pp. 1-28. 
que generan a nivel mundial, europeo y nacional los tráficos de ilícitos más lucrativos. Y, por otro lado, se examinará la regulación de los principales instrumentos penales para combatir el enriquecimiento ilícito que genera la criminalidad transnacional (la pena de multa proporcional, el decomiso de ganancias y la responsabilidad civil), haciendo especial referencia a sus fines político-criminales ${ }^{20}$.

Combinando las conclusiones alcanzadas en relación con cada uno de estos aspectos se podrá determinar si la regulación vigente resulta eficaz en términos de prevención general negativa.

\section{Las ganancias ilícitas de la delincuencia transnacional}

El conocimiento de la incidencia y la prevalencia de la delincuencia transnacional constituye una tarea extremadamente compleja y representa un reto que requiere de cualificados esfuerzos ${ }^{21}$. En consecuencia, todavía más difícil es determinar la cuantía resultante de sus ganancias ilícitas, teniendo en cuenta, además, la elevada cifra negra que debe presuponerse en este ámbito.

20 Téngase en cuenta que no se trata de un estudio monográfico acerca de la responsabilidad civil, el decomiso y la pena de multa proporcional, por lo que la bibliografía no pretende ser exhaustiva ni tampoco el análisis dogmático.

21 Tres son los principales obstáculos que, según han puesto de manifiesto los especialistas, limitan la medición del crimen organizado: impedimentos de tipo conceptual, las peculiaridades de su medición y el acceso a datos. Las explicaciones de cada uno de ellos se pueden leer en el documento "La Lucha contra el Crimen contra el crimen organizado en la Unión Europea" del Centro Superior de Estudios de la Defensa Nacional (2012), disponible en: https://publicaciones.defensa.gob.es/lalucha-contra-el-crimen-organizado-en-la-union-europea.html (última consulta: 11/01/2021). También sobre estas dificultades, véase DELCARPIO-DELGADO, J.: «El paradigma del volumen del patrimonio criminal y de su blanqueo», en DEL-CARPIO-DELGADO, J. (Dir.), Criminalidad en un mundo global, Valencia, 2020, pp. 397-435. 
Con todo, según el estudio Transnational Crime and the Developing World de la Fundación Global Financial Integrity, en su versión de 2017 (la última publicada hasta el momento ${ }^{22}$, la delincuencia transnacional movería entre 1,5 y 2 billones de euros anualmente en todo el mundo. Este informe divide los mercados criminales en 11 categorías: el tráfico de drogas, armas, seres humanos, órganos humanos y bienes culturales, la falsificación, el tráfico ilegal de animales salvajes, la pesca ilegal, la tala ilegal, la minería ilegal y el robo de petróleo crudo. Entre ellas, la actividad criminal más lucrativa sería el tráfico de drogas, seguida del tráfico de armas y de la trata de personas, que son, precisamente, los fenómenos en los que vamos a centrar el presente trabajo ${ }^{23}$.

Por lo que se refiere a España, debido a la obligación impuesta en 2014 por Eurostat de incorporar a la contabilidad nacional la estimación en la Renta Nacional Bruta de los flujos provenientes de algunas actividades ilegales a efectos informativos, se puede contar con un dato de interés. El Instituto Nacional de Estadística ha incorporado desde entonces estimaciones en la contabilidad nacional sobre algunas de las actividades que considera ilegales, suponiendo estas el $0,87 \%$ del Producto Interior Bruto nacional, unos 10.500 millones

22 El documento está disponible en: https://gfintegrity.org/report/transnational-crime-and-the-developing-world/ (última consulta: 10/01/2021).

23 Se señala en la Orden PCI/161/2019, de 21 de febrero, por la que se publica el Acuerdo del Consejo de Seguridad Nacional, por el que se aprueba la Estrategia Nacional contra el Crimen Organizado y la Delincuencia Grave que el mercado ilegal de armas se configura como una de las actividades criminales que más beneficio ilícito generan a nivel mundial, si bien en España no se presenta en la actualidad un tráfico que pudiera catalogarse como de gran escala. Con todo, según el Informe anual de Seguridad Nacional 2019, disponible en: https:/www.dsn.gob.es/es/documento/ informe-anual-seguridad-nacional-2019, (fecha de acceso: 11/01/2021), las principales amenazas del crimen organizado siguen siendo el tráfico de drogas, el blanqueo de capitales, el cibercrimen y el tráfico ilícito de armas (p. 41). Por lo tanto, también los fenómenos criminales objeto del presente trabajo se sitúan entre los más preocupantes en España. 
de euros en 2017, lo que da una idea del impacto económico estimado que representan parte de las actividades ilegales en España ${ }^{24}$.

A continuación, entendemos relevante para justificar nuestro estudio examinar las estimaciones publicadas acerca de las ganancias ilícitas de cada uno de los fenómenos criminales seleccionados.

\subsection{El tráfico de drogas}

Las Naciones Unidas aprobaron en 1988 la Convención de Viena «conscientes de que el tráfico ilícito genera considerables rendimientos financieros y grandes fortunas que permiten a las organizaciones delictivas transnacionales invadir, contaminar y corromper las estructuras de la administración pública, las actividades comerciales y financieras lícitas y la sociedad a todos sus niveles», así como «deseosas de eliminar las causas profundas del problema del uso indebido de estupefacientes y sustancias sicotrópicas, comprendida la demanda ilícita de dichas drogas y sustancias y las enormes ganancias derivadas del tráfico ilícito».

El mercado mundial del narcotráfico habría obtenido beneficios de entre 350.000 y 550.000 millones de euros en $2014^{25}$. Pero esta cifra se estima conservadora, pues no incluye el valor que generan las nuevas sustancias psicoactivas ${ }^{26}$.

24 Orden PCI/161/2019, de 21 de febrero, por la que se publica el Acuerdo del Consejo de Seguridad Nacional, por el que se aprueba la Estrategia Nacional contra el Crimen Organizado y la Delincuencia Grave.

25 Estudio Transnational Crime and the Developing World de la Fundación Global Financial Integrity, en su versión de 2017, disponible en: https:// gfintegrity.org/report/transnational-crime-and-the-developing-world/ (fecha de acceso: 11/01/2021).

26 El mercado europeo de drogas sintéticas estaría evolucionando rápidamente. Dentro del mercado de estimulantes, estas drogas competirían por la cuota de mercado junto con la cocaína. El valor del mercado en la Unión Europea para anfetaminas en 2017 se estima en al menos 1.000 millones de euros. Al respecto, véase el "EU Drug Markets Report 2019" 
El cannabis representaría el submercado que más beneficios genera, habiendo obtenido en 2014 entre 155.000 y 240.000 millones de euros a nivel mundial. Esto se debe a que esta es la droga más cultivada, distribuida y consumida ${ }^{27}$.

En Europa se estima que el tráfico de drogas originaría un mínimo de 30.000 millones de euros al año ${ }^{28}$. El mayor mercado de drogas también lo generaría el cannabis, que, con alrededor de 25 millones de usuarios anuales, habría conseguido en 2017 ganancias por un valor mínimo de 11.600 millones de euros ${ }^{29}$.

Finalmente, en cuanto a España, aunque no se han localizado estimaciones sobre las ganancias que genera el

de Europol, disponible en: https://www.europol.europa.eu/newsroom/ news/2019-eu-drug-markets-report-emcdda-and-europol\#: :text $=\% 20$ 2019\%20EU $\% 20$ DRUG $\% 20$ MARKETS $\% 20$ REPORT $\% 20$ FROM $\% 20$ THE, The $\% 20$ report $\% 20$ takes $\% 20$ an $\% 20$ in-depth $\% 201$ ook...\%20 More $\% 20$ (última consulta: 10/01/2021), p. 17.

27 En 2014 se estimó que 182,5 millones de personas, es decir, el 2,5 por ciento de la población mundial, lo consumió. Al respecto, véase el ya citado Informe "Transnational Crime and the Developing World" de la Fundación Global Financial Integrity (2017).

28 Véase, al respecto, el "EU Drug Markets Report 2019" de Europol anteriormente mencionado. Sorprendentemente, la cifra que ofrece el Informe "Serious and organised crime threat assessment" de Europol, publicado en 2017 (conocido como "SOCTA 2017"), disponible en: https://www.europol.europa.eu/socta/2017/ (último acceso: 10/01/2021), p. 34, son 24 billones de euros al año; una cifra muy superior a la que ha estimado esta misma organización dos años después.

29 La cocaína habría supuesto en 2017 unos 9.100 millones de euros (según el SOCTA 2017, p. 37, serían, en cambio, 5,7 billones de euros al año). Y el uso de heroína y otros opioides habría representado en 2017, como mínimo, 7.400 millones de euros. No obstante, según Europol, existen indicios de que la disponibilidad de heroína en la Unión Europea podría aumentar. Recientes estimaciones de producción de opio de Afganistán, niveles de incautaciones en Turquía y las evaluaciones de inteligencia de la actividad a lo largo de las principales rutas de tráfico a Europa son todas elevadas, y se han detectado grandes partidas de heroína dentro de la Unión Europea. Véase, al respecto, el "EU Drug Markets Report 2019” de Europol. 
tráfico de drogas, según la Orden PCI/161/2019, de 21 de febrero, por la que se publica el Acuerdo del Consejo de Seguridad Nacional, por el que se aprueba la Estrategia Nacional contra el Crimen Organizado y la Delincuencia Grave, a medio plazo, es previsible que continúe la especial importancia de los mercados criminales relacionados con la cocaína y el cannabis. Y, a largo plazo, es probable que se incremente la amenaza procedente de los mercados ilícitos relativos a las drogas de síntesis y nuevas sustancias psicoactivas.

\subsection{El tráfico de armas}

El tráfico de armas es un fenómeno criminal en expansión que afecta a todas las partes del mundo, impactando en la sociedad de diversas formas. Constituye uno de los principales problemas en el contexto de la seguridad y se encuentra en el foco de los esfuerzos por el mantenimiento del orden. Específicamente, las armas de fuego contribuyen decisivamente a la violencia, incrementan el número de homicidios $^{30}$ y cumplen con frecuencia un papel fundamental en la delincuencia organizada, amplificando la incidencia de los conflictos armados y el terrorismo ${ }^{31}$.

Por estas razones, entre otras, la comunidad internacional se ha comprometido a «reducir considerablemente

30 En el Global Study on Firearms Trafficking 2020 de la UNODC, disponible en: https://www.unodc.org/unodc/en/firearms-protocol/firearmsstudy.html (fecha de acceso: 11/01/2021), se afirma que «más del 50 por ciento de los homicidios que se producen en el mundo se llevan a cabo con un arma de fuego», pág. 13.

31 Ibidem, pág. 2. Concretamente, se afirma que en 2017 los civiles poseían 35 millones de armas de fuego ilícitas en la Unión Europea (el 56\% del total estimado de armas de fuego). Es decir, de acuerdo con estas estimaciones, las armas de fuego ilícitas superarían en número a las armas de fuego de posesión legal. Véase, al respecto, la Comunicación de la Comisión al Parlamento Europeo, al Consejo, al Comité Económico y Social Europeo, y al Comité de Regiones. Plan de Acción de la UE sobre el Tráfico de armas de fuego 2020-2025, de 24 de julio de 2020 [COM(2020) 608 final], disponible en: https://eur-lex.europa.eu/legal-content/ES/ TXT/?uri=CELEX:52020DC0608 (fecha de acceso: 11/01/2021). 
las corrientes financieras y de armas ilícitas», compromiso reflejado en la meta 16.4 de la Agenda 2030 de Desarrollo sostenible de Naciones Unidas ${ }^{32}$.

En respuesta a estas demandas internacionales, desde hace unos años se está realizando un importante esfuerzo por parte de las Fuerzas y Cuerpos de Seguridad españolas para combatir el tráfico de armas. Esto es, al menos, lo que se desprende de la evolución del número de armas incautadas en las intervenciones de la Guardia Civil por la comisión de ilícitos penales y puestas a disposición judicial, que han ascendido de 7.649 armas en 2013 a 14.996 en $2019^{33}$. Sin embargo, parecen escasas las políticas alternativas a la incautación adoptadas para la prevención del fenómeno.

Los datos disponibles acerca de las ganancias ilícitas procedentes del tráfico de armas, tal y como se afirma desde Naciones Unidas, se consideran demasiado esporádicos como para poder conformar una base empírica ${ }^{34}$. A pesar de

32 Resolución aprobada por la Asamblea General el 25 de septiembre de 2015: la Agenda 2030 para el Desarrollo Sostenible (A/RES/70/1). En la meta 16.4 se exhorta específicamente a los Estados a «reducir significativamente las corrientes financieras y de armas ilícitas, fortalecer la recuperación y devolución de los activos robados y luchar contra todas las formas de delincuencia organizada». Uno de los indicadores para medir el logro de esta meta es la proporción de armas de fuego incautadas cuyo origen ilícito se ha determinado. Según el Global Study on Firearms Trafficking 2020 de la UNODC, disponible en: https://www. unodc.org/unodc/en/firearms-protocol/firearms-study.html (fecha de acceso: 10/01/2021), el total de armas incautadas en los 81 países participantes en este estudio ascendía a aproximadamente 550.000 en cada uno de los años 2016 y 2017. Y, en cuanto a las municiones, para 45 países, se incautaron un total de 3 millones de cartuchos en 2016 y 7,9 millones de cartuchos en 2017.

33 Esta información se ofrece en el Informe anual de Seguridad Nacional 2019, aprobado el 4 de marzo de 2020, disponible en: https://www.dsn. gob.es/es/documento/informe-anual-seguridad-nacional-2019, (fecha de acceso: 12/01/2021), pág. 43.

34 Global Study on Firearms Trafficking 2020 de la UNODC, disponible en: https://www.unodc.org/unodc/en/firearms-protocol/firearms-study. html (fecha de acceso: 11/01/2021), pág. 2. 
ello, el estudio Transnational Crime and the Developing World de la Fundación Global Financial Integrity sostiene que el tráfico de armas generaría entre 1.400 y 3.000 millones de euros anuales ${ }^{35}$.

Por lo que se refiere a España, a pesar de haberse situado ya como el séptimo país exportador mundial de armas $^{36}$, hasta la fecha no se han detectado grandes redes delictivas dedicadas específicamente al tráfico de armas como actividad principal. Pero, como ha advertido recientemente el Consejo de Seguridad Nacional, no se puede minusvalorar la gravedad de esta actividad que se materializa con la presencia de pequeñas organizaciones policriminales, incluso delincuentes autónomos especializados, que proveen de forma circunstancial tanto al crimen organizado como a la delincuencia grave de distintos tipos de $\operatorname{armas}^{37}$.

Por ello, durante los últimos años se han llevado a cabo diversas operaciones de envergadura frente al tráfico de armas. En 2019 España ha coordinado una operación policial internacional que ha culminado con la detención de 175

35 Una cifra sustancialmente inferior ofrecía la UNODC en 2010: entre 150 y 270 millones de euros al año; es decir, entre el 10 y el $20 \%$ del mercado lícito. Véase, al respecto, "La delincuencia organizada se ha globalizado convirtiéndose en una amenaza para la seguridad", Boletín de Prensa de 3 de junio de 2010, disponible en: https://www.unodc.org/ documents/data-and-analysis/tocta/GlobalizationofCrime-PR-FinalSpanish.pdf (fecha de acceso: 11/01/2021).

36 España se sitúa como país exportador de armas, por detrás de EE.UU. $(29 \%)$, Rusia $(27 \%)$, Alemania $(7 \%)$, China $(6 \%)$, Francia $(5 \%)$ y Reino Unido (4\%), con una cuota del 3\% global y una cifra anual que desde 2016 supera los 4.000 millones de euros (en 2008 no alcanzaba los 1.000 millones). Sobre esta información, véase el Informe de Amnistía Internacional sobre el tráfico de armas en España, disponible en: https:// www.es.amnesty.org/en-que-estamos/espana/armas/ (última consulta: 10/01/2021).

37 Orden PCI/161/2019, de 21 de febrero, por la que se publica el Acuerdo del Consejo de Seguridad Nacional, por el que se aprueba la Estrategia Nacional contra el Crimen Organizado y la Delincuencia Grave. 
personas en diversos países de Europa ${ }^{38}$. Y en junio de 2020 la Policía Nacional ha detenido a 21 personas en un operativo desarrollado en 15 provincias españolas en el que se han incautado 731 armas, algunas de ellas de guerra, así como material explosivo y detonadores. No obstante, aunque la organización ha sido desmantelada a nivel nacional, los investigadores todavía tratan de averiguar posibles conexiones internacionales de los arrestados ${ }^{39}$.

\subsection{El tráfico de personas}

Según el Transnational Crime and the Developing Word de 2017, la trata de personas generaría más de 150.000 millones de euros al año, convirtiéndose en la tercera actividad criminal transnacional más lucrativa del mundo. Sin embargo, deben tenerse en consideración los siguientes matices: en primer lugar, que al confeccionar estas estimaciones no solo se ha tenido en cuenta el beneficio que genera el fenómeno de la trata de personas, sino también el del tráfico ilícito de migrantes que la favorece (pues se analiza la trata transnacional de personas). En segundo lugar, debe advertirse que al estimar los beneficios no solo se considera la trata de personas sino también la explotación posterior. Y, en tercer lugar, ha de subrayarse que solo se ha tenido en cuenta el beneficio que reporta la trata de personas con fines de explotación sexual y laboral, pero no se han estimado los que generaría la

38 Esta operación se enmarca dentro del Plan de Acción Operativo 2019 de la llamada "Empact firearms" (European Multidisciplinary Platform Against Criminal Threats), una plataforma que lidera e impulsa la acción coordinada de los países de la Unión Europea contra el tráfico de armas. Véase, al respecto, la noticia publicada por el Departamento de Seguridad Nacional en la web del Gabinete de la Presidencia del Gobierno, disponible en: https://www.dsn.gob.es/es/actualidad/seguridadnacional-ultima-hora/nacional- $\%$ E2\%80\%93-lucha-contra-crimen-organizado-147 (fecha de acceso: 10/01/2021).

$39 \mathrm{Al}$ respecto, véase la nota de prensa publicada por el Ministerio del Interior: http://www.interior.gob.es/prensa/noticias/-/asset_publisher/ GHU8Ap6ztgsg/content/id/12027246 (fecha de acceso: 11/01/2021). 
trata de personas con fines de extracción de órganos, para la celebración de matrimonios forzados o para la realización de actividades delictivas, entre otras modalidades ${ }^{40}$.

En el seno de este amplio fenómeno al que denominamos "tráfico de personas" deben distinguirse dos modalidades bien diferenciadas: la trata de personas y el tráfico ilegal de migrantes, que han dado lugar a sendos protocolos complementarios a la Convención de Palermo: el Protocolo para prevenir, reprimir y sancionar la trata de personas, especialmente mujeres y niños y el Protocolo contra el tráfico ilícito de migrantes por tierra, mar y aire.

Son varias las diferencias entre ambos fenómenos que pueden ser subrayados. Mientras que el tráfico ilícito de migrantes siempre tiene un elemento transnacional, en la trata de seres humanos este elemento no es necesario. Además, el tráfico ilícito de migrantes debe contar con la libre voluntad de la persona objeto del tráfico y la trata de personas resulta siempre de la ausencia de voluntad del sujeto pasivo. Otra diferencia entre ambos fenómenos es que mientras que la trata de personas para la explotación siempre tiene como finalidad la obtención de un beneficio, el favorecimiento de la inmigración clandestina se puede realizar por cuestiones humanitarias ${ }^{41}$. Finalmente, PÉREZ ALONSO agrega las siguientes diferencias entre ambos fenómenos: en primer lugar, que la inmigración clandestina supone la vulneración de la política migratoria del Estado receptor, por lo que afecta al interés estatal en el control del tránsito fronterizo de personas y, por el contrario, la trata de seres humanos supone una violación de la dignidad personal y de la integridad moral

40 De hecho, en el mismo informe se analiza el lucro obtenido por el crimen transnacional a través del tráfico de órganos humanos de un modo independiente y se estima que generaría entre 730 y 1.500 millones de euros anualmente.

41 PÉREZ CEPEDA, A.I.: Globalización, tráfico internacional ilicito de personas y derecho penal, Granada, 2004, pp. 26 y 27 
de la persona; en segundo lugar, que los migrantes objeto de tráfico en el caso de la migración clandestina tienen la consideración legal de objeto del tráfico y en el caso de la trata de seres humanos se les califica legalmente como víctimas; y, en tercer lugar, que en la migración clandestina no se establece ningún tipo de distinción en atención a la edad de la persona objeto del tráfico y en el caso de la trata de seres humanos se da un tratamiento especial cuando la persona traficada es un menor ${ }^{42}$.

En coherencia con lo anterior, las estimaciones que se han localizado en otros informes sobre la materia han abordado ambos fenómenos por separado.

Así, respecto de la trata de personas, la Organización Internacional del Trabajo estima que genera aproximadamente 127.000 millones de euros cada año ${ }^{43}$. Los mayores beneficios anuales provendrían de la explotación sexual forzada (más de 83.000 millones de euros), con un beneficio anual medio de 18.000 euros por víctima ${ }^{44}$. La explotación laboral forzada afectaría al mayor número de víctimas (14,2 millones, $68 \%$ ) porque hay muchas más industrias involucradas (por ejemplo, construcción, minería y agricultura), pero generaría menos beneficios (43.000 millones de euros) que la explotación sexual. El beneficio anual promedio por víctima sería de 1.700 euros de la mano de obra doméstica y de 1.800 a 3.400 euros de mano de obra no doméstica.

Por su parte, en relación con el tráfico ilícito de migrantes, la Resolución 54/212 de la Asamblea General de Naciones Unidas, de 22 de diciembre de 1999, ya apuntó que las

42 Al respecto, PÉREZ ALONSO, E.: Tráfico de personas e inmigración clandestina, Valencia, 2008, pp. 155-156.

43 Informe "Transnational Crime and the Developing World" de la Fundación Global Financial Integrity (2017).

44 La industria del sexo es ilícita en sí misma, por lo que los precios, y por lo tanto los beneficios, se elevan debido al riesgo, a pesar de que hay tres veces menos víctimas (4,5 millones) que en el trabajo forzoso. 
causas fundamentales del fenómeno residían en la pobreza de las víctimas y los beneficios que la migración internacional podía reportar a los interesados.

Según el Global Study on Smuggling of Migrants 2018 de la UNODC, hay pruebas de que, como mínimo, 2,5 millones de migrantes fueron traficados y generaron entre 4.600 y 6.000 millones de euros en $2016^{45}$. En 2015, en cambio, se habrían generado aproximadamente 5 billones de euros, por lo que se identifica una tendencia descendente en cuanto al número de inmigrantes irregulares ${ }^{46}$.

\section{Instrumentos penales para desincentivar económicamente la delincuencia transnacional. Especial referencia a sus fines político-criminales}

Una vez presentadas las estimaciones publicadas acerca de las ganancias ilícitas generadas por los principales fenómenos criminales transnacionales a nivel mundial, europeo y nacional, corresponde detenernos, aunque sea brevemente, en los principales instrumentos ubicados en el Libro I del Código penal español dirigidos a combatir el enriquecimiento derivado de la delincuencia transnacional.

Como ya anunciamos al inicio de estas páginas, nos estamos refiriendo a la responsabilidad civil derivada del delito, al decomiso de ganancias y a la pena de multa proporcional.

Aunque las tres se regulan en la Parte General del Código Penal, solo las dos primeras son de aplicación a cualquier delito en el que se identifique un perjuicio material o

45 El Global Report on Trafficking in persons 2018 de la UNODC, disponible en: https://www.unodc.org/documents/data-and-analysis/ glotip/2018/GLOTiP_2018_BOOK_web_small.pdf (última consulta: $11 / 01 / 2021$ ), por el contrario, no se refiere a los beneficios económicos que genera la trata de personas.

46 Informe SOCTA 2017, p. 50. 
moral, por un lado, o un beneficio ilícito, por otro. La multa proporcional, sin embargo, se reserva para un reducido $n u$ merus clausus de delitos, dentro de los cuales no se encuentran todos los delitos de tráficos de ilícitos.

Señalado lo anterior, a continuación, haremos una breve referencia a la regulación de cada una de estas herramientas, centrándonos en aquellos aspectos de política criminal que nos puedan resultar de especial utilidad para nuestro estudio.

\subsection{El decomiso de ganancias}

En lo que al ordenamiento español se refiere, el decomiso se regula en el Título VI del Libro Primero del Código Penal, dedicado a las consecuencias accesorias ${ }^{47}$. Este instrumento jurídico ha sufrido una profunda modificación con la reforma operada a través de la Ley Orgánica 1/2015, de 30 de marzo, ampliando sustancialmente su ámbito de aplicación ${ }^{48}$.

47 Nos estamos refiriendo al carácter sustantivo del decomiso ya que en la Ley de Enjuiciamiento Criminal se reserva el Título III ter a la intervención de terceros afectados por el decomiso y al procedimiento de decomiso autónomo, a partir de la Ley 41/2015, de 5 de octubre.

48 Al respecto, AGUADO CORREA, T.: "Cinco años después de las reformas del decomiso: does crime still pay?", en BERDUGO GÓMEZ DE LA TORRE, I./ RODRÍGUEZ GARCÍA, N., (Eds.), Decomiso y recuperación de activos crime doesn't pay, Valencia, 2020, pp. 62-76; NEIRA PENA, A.M.: "Decomiso: entre garantismo y eficacia. Las presunciones legales sobre el origen ilícito de los bienes", en BERDUGO GÓMEZ DE LA TORRE, I./ RODRÍGUEZ GARCÍA, N., (Eds.), Decomiso y recuperación de activos crime doesn't pay, Valencia, 2020, pp. 90-99; PUEYO RODERO, J.A.: "La nueva regulación del comiso en el Código Penal”, en Cuadernos penales José María Lidón, nº 15, 2019, pp. 113-127; GRANADOS MUÑOZ, C.: "El decomiso de los bienes, efectos o ganancias procedentes del delito", en Revista Jurídica de Castilla y León, no 48, mayo 2019, pp. 97-108; CARRILLO DEL TESO, A.E.: Decomiso y recuperación de activos en el sistema penal español, ob. cit., pp. 95 y ss.; ROIG TORRES, M.: "La regulación del comiso. El modelo alemán y la reciente reforma española", en Estudios Penales y Criminológicos, vol XXXVI, 2016, pp. 227-266; DÍAZ CABIALE, J.A.: 
Y, en este mismo sentido, se han reformado recientemente las legislaciones de otros países de nuestro entorno ${ }^{49}$, en cumplimiento de los compromisos internacionales adquiridos.

El decomiso supone la «privación con carácter definitivo de bienes por decisión de un tribunal o de otra autoridad competente», tal y como indica la Convención de Palermo en su artículo 2.g $)^{50}$. Dichos bienes pueden constituir el resultado, el producto o el beneficio derivado del delito o ser el objeto, equipo o instrumentos utilizados, o destinados a utilizarse, para cometer el delito (art. 12.1 Convención de Palermo).

"El decomiso tras las reformas del Código Penal y la Ley de Enjuiciamiento Criminal de 2015”, ob. cit., pp. 6-68; QUINTERO OLIVARES, G.: "El comiso tras la reforma del Código penal (LO 1/2015, de 30 de marzo)", ob. cit., pp. 42-51; y GORJÓN BARRANCO, Ma C.: "El comiso ampliado como paradigma del moderno Derecho Penal", en Revista Penal, n 38, 2016, pp. 133-137.

49 Sobre la evolución histórico-legislativa del decomiso en España, véase ampliamente; CASANUEVA SANZ, I./ GIL NOBAJAS, M ${ }^{\mathrm{a}}$ S./ ARMAZA ARMAZA, E.J.: "La decisión marco 2005/212: Antecedente y origen de las últimas reformas del comiso como consecuencia accesoria”, en Estudios de Deusto: revista de la Universidad de Deusto, vol. 66, $\mathrm{n}^{\circ}$ 2, 2018, pp. 401-406, 419-434.

Sobre la evolución del Derecho europeo y el decomiso, véanse QUINTERO OLIVARES, G.: "El comiso tras la reforma del Código penal (LO 1/2015, de 30 de marzo)", en Cuadernos penales José María Lidón, $\mathrm{n}^{\circ}$ 12, 2016, pp. 51-54; CARRILLO DEL TESO, A.E.: "La Directiva 2014/42/UE sobre el embargo y el decomiso de los instrumentos y del producto del delito en la UE: decomiso ampliado y presunción de inocencia", en Revista de Estudios Europeos, no extraordinario monográfico, 1, 2017, pp. 20-32; en general, sobre la regulación del decomiso en el ámbito internacional, puede verse, DÍAZ CABIALE, J.A.: "El decomiso tras las reformas del Código Penal y la Ley de Enjuiciamiento Criminal de 2015", en Revista electrónica de ciencia penal y criminología, $n^{\circ} 18,2016$, pp. 4-6.

50 De modo similar se pronuncia la Directiva 2014/42/UE del Parlamento Europeo y del Consejo, de 3 de abril de 2014, sobre el embargo y el decomiso de los instrumentos y del producto del delito en la Unión Europea, en el artículo 2.4). Sobre la discusión doctrinal existente en torno al decomiso, véase ampliamente CARRILLO DEL TESO, A.E.: Decomiso y recuperación de activos en el sistema penal español, Valencia, 2018, pp. 96-129. 
En consecuencia, en el artículo 127.1 del Código Penal español se establece que «[t]oda pena que se imponga por un delito doloso llevará consigo la pérdida de los efectos que de él provengan y de los bienes, medios o instrumentos con que se haya preparado o ejecutado, así como de las ganancias provenientes del delito, cualesquiera que sean las transformaciones que hubieren podido experimentar».

Teniendo en cuenta estas definiciones, se puede identificar un doble fundamento en la institución. Por un lado, el decomiso se basa en la peligrosidad de los objetos e instrumentos del delito y en la probabilidad de que sean usados en el futuro para la comisión de nuevos delitos ${ }^{51}$; y por otro, en la necesidad de anular la ventaja obtenida por el delito, siendo necesario para ello privar al delincuente de los objetos obtenidos mediante la comisión del delito (STS 483/2007, de 4 de junio). En este sentido, con el decomiso se busca que el delito no resulte provechoso ${ }^{52}$. Es decir, se configura, tal y como advierte RODRÍGUEZ GARCÍA, como un «instrumento jurídico mágico [...] vendido públicamente a los ciudadanos anudado a una nueva política criminal que busca alcanzar mayores niveles de efectividad en el combate de todas aquellas formas delictivas graves y complejas» de las que se derivan grandes beneficios económicos ${ }^{53}$. Estas formas delictivas, tal y como se ha venido indicando aquí, adquieren su máximo desarrollo en el plano transnacional bajo la dirección de una organización criminal. En esta dirección,

51 GRACIA MARTÍN, L.: "Consecuencias jurídicas no penales derivadas de la comisión del delito (I)”, en GRACIA MARTÍN, L. (Coord.). Lecciones de consecuencias jurídicas del delito, Valencia, 2016, p. 235.

52 AGUADO CORREA, T.: "Cinco años después de las reformas del decomiso: does crime still pay?", ob. cit., p. 55

53 RODRÍGUEZ GARCÍA, N.: "El decomiso en el sistema penal español: análisis de contexto y lineamientos para una mejor intelección”, en BERDUGO GÓMEZ DE LA TORRE, I./ RODRÍGUEZ GARCÍA, N., (Eds.), Decomiso y recuperación de activos crime doesn't pay, ob. cit., p. 22. 
el mismo autor señala que los denominadores comunes de los delitos que justifican la existencia del decomiso son: la comercialización de bienes y servicios ilegales, «de manera tal que coexiste un mercado legal de bienes, productos y servicios con otro ilegal», el ánimo de lucro, «el empleo de la lógica empresarial, impulsada por un más que positivo análisis coste/beneficio», la alarma social y los «efectos para la integridad institucional, y el desarrollo económico, político y social de los países $\rangle^{54}$.

No obstante lo anterior, el decomiso se matiza a través del principio de proporcionalidad (art. $128 \mathrm{CP}$ ). De este modo, se otorga potestad al juzgador para que no lo decrete, o lo haga parcialmente, en los casos en los que los efectos derivados del delito y los instrumentos utilizados para su comisión pertenezcan al comercio lícito y su valor no resulte proporcional con la naturaleza o gravedad de la infracción penal, o en aquellos supuestos en los que se haya satisfecho la responsabilidad civil. De manera que el decomiso se configura como la regla general y no decretarlo será la excepción ${ }^{55}$. Sin embargo, como nos recuerda DÍAZ CABIALE, «el Estado no padece el síndrome de Diógenes»y, por lo tanto, no tiene sentido decomisar siempre los instrumentos utilizados en la ejecución de un delito doloso ${ }^{56}$. Esto solo deberá hacerse cuando cumpla con su finalidad principal que será

54 RODRÍGUEZ GARCÍA, N.: "En la búsqueda de un sistema penal más eficaz en el combate a la corrupción: expectativas depositadas en el decomiso", en Revista Internacional Transparencia e Integridad, $\mathrm{n}^{\circ} 1$, mayo-agosto, 2016, pp. 3 y ss.

55 AGUADO CORREA, T.: "Decomiso de los productos de la delincuencia organizada. Garantizar que el delito no resulte provechoso", en Revista Electrónica de Ciencia Penal y Criminología, no 15-05, 2013, p. 21, considera que la previsión del artículo 128 del Código Penal es un límite mínimo para acordar el decomiso.

56 DÍAZ CABIALE, J.A., "El decomiso tras las reformas del Código Penal y la Ley de Enjuiciamiento Criminal de 2015", ob. cit., p. 11, pone el ejemplo de la improcedencia de decomisar el vehículo en un delito contra la seguridad vial relativo a exceso de tasa de alcohol. 
preventivo-general y preventivo-especial ${ }^{57}$. Y esta doble finalidad se satisface únicamente en aquellos delitos motivados por la obtención de un beneficio económico: ¿qué desincentivo para lesionar a otro se derivará de confiscar una piedra o una navaja? De hecho, el principio de oportunidad no es de aplicación a las ganancias y a sus transformaciones. Se refiere solo, al menos literalmente, a los efectos e instrumentos del delito $^{58}$.

Pues bien, la importancia atribuida al decomiso en el marco de la delincuencia transnacional se pone de manifiesto claramente en el Protocolo contra la fabricación y el tráfico ilícitos de armas de fuego, sus piezas y componentes y municiones (art. 6) y en la Convención contra el Tráfico ilícito de estupefacientes y sustancias sicotrópicas (art. 5). Ambos contemplan expresamente el decomiso como mecanismo para atacar las ganancias ilícitas. Sin embargo, ni en estas normas ni en el resto de los instrumentos internacionales examinados, a pesar de contener apartados específicos dedicados a la prevención, se hace alusión alguna a otros modos de conseguir esta misma finalidad, como sería la previsión de penas pecuniarias.

\subsection{La responsabilidad civil derivada del delito}

La responsabilidad civil ex delicto se encuentra prevista en el Título V del Libro Primero del Código Penal.

57 ROIG TORRES, M., "La regulación del comiso. El modelo alemán y la reciente reforma española", ob. cit., p. 268. La autora sostiene que «el decomiso no es una sanción penal, sino una medida sui generis, que tiene por objeto disuadir de la comisión de delitos que se realizan con un fin lucrativo, estableciendo que la condena supondrá la privación de todos los bienes relacionados con el hecho o de una suma proporcional. Se trata, pues, de una respuesta que pretende atajar las expectativas de obtener rendimientos económicos a través de operaciones delictivas».

58 LORENTE PABLO, E.: "La investigación patrimonial: aspectos prácticos del decomiso y de la recuperación de activos", en BERDUGO GÓMEZ DE LA TORRE, I./ RODRÍGUEZ GARCÍA, N., (Eds.), Decomiso y recuperación de activos crime doesn't pay, ob. cit., p. 842 
En concreto, en el Capítulo I De la responsabilidad civil y su extensión (arts. 109-115) en relación con el Capítulo II De las personas civilmente responsables (arts. 116-122). Tal y como ahí se establece, la responsabilidad civil comprende la eventual restitución del bien, si esto fuera posible, «con el abono de los deterioros y menoscabos» que se hayan producido (art. 111); la reparación del daño (art. 112) y la indemnización de perjuicios materiales y morales, donde se tiene en cuenta, también, aquellos que se «hubieren irrogado a sus familiares o terceros» (art. 113).

Por lo tanto, se trata de un instrumento político-criminal que puede llegar a anular el enriquecimiento que el delito proporciona a su autor y, en consecuencia, puede actuar con un efecto intimidador ${ }^{59}$. Al menos, no cabe ninguna duda de que esto sucede con la indemnización de perjuicios materiales y morales. Con independencia de las discusiones interpretativas, la doctrina mayoritaria considera que el perjuicio comprende los efectos lesivos derivados de la infracción ${ }^{60}$. Dentro de estos, se encuentran los daños o perjuicios con valor económico pero también aquellos otros como el dolor por la pérdida de un ser querido, el sufrimiento físico, el deshonor, desprestigio, etc. ${ }^{61}$. Entendemos que tampoco debería plantear problemas admitir que la reparación del daño y la restitución del bien afectan a las ganancias ilícitas.

59 Así se hace eco de ello HORTAL IBARRA, J.C., "La naturaleza jurídica de la responsabilidad civil ex delicto: o cómo "resolver" la cuadratura del círculo", en Indret, n ${ }^{\circ} 4$, octubre, 2014, p. 12, en su nota 45, aludiendo a ANTÓN ONECA o a MIR PUIG. Sobre la discusión en torno a la naturaleza de la responsabilidad civil ex delicto, ámpliamente el mismo, 2014, pp. 8-12.

60 AlASTUEY DOBÓN, C.: "Artículo 110”, en GÓMEZ TOMILlO, M. (Dir.), Comentarios Prácticos al Código Penal. Tomo I. Parte General. Artículos 1-137, Aranzadi, Pamplona, 2015, p. 900.

61 Ibidem, p. 910, recopila una amplia jurisprudencia en la que se enumeran los daños morales que pueden tener cabida en la cuantificación de la responsabilidad civil derivada del delito. 
En la medida en que ambas acciones suponen un perjuicio para el patrimonio del sujeto activo, aunque ese patrimonio fuera en parte ilegítimo, actuarán como instrumentos disuasorios por afectar al beneficio derivado del delito. De hecho, en algunas sentencias se establece, aunque el Código penal no se pronuncie en estos términos, que la cantidad a satisfacer en concepto de responsabilidad civil comprende «tanto el daño moral causado como las ganancias obtenidas ${ }^{62}$.

No obstante, que en ocasiones la ganancia ilícita y el perjuicio patrimonial puedan coincidir no significa que ambos conceptos tengan el mismo contenido. Incluso en los casos en que existe tanto perjuicio como ganancia, la cuantía de ambos conceptos puede no corresponderse. Sirvan de ejemplo algunas de las sentencias condenatorias dictadas en aplicación del delito de trata de personas. En ellas la responsabilidad civil ex delicto no puede garantizar, por sí misma, que el delito no ha resultado económicamente provechoso. De hecho, la responsabilidad civil se limita al pago de una indemnización a la víctima de entre 5.000 y 10.000 euros, mientras que las ganancias que se obtienen en este ámbito se estiman, aproximadamente, en 20.000 euros al año por cada víctima $^{63}$. En definitiva, aunque la responsabilidad civil derivada del delito puede llegar a anular el enriquecimiento que trae causa de un delito, ni sirve solo para eso, ni lo consigue en todos los $\operatorname{casos}^{64}$.

62 Sirvan de ejemplo la STSJ Cataluña 123/2019 y la SAP Baleares $346 / 2019$.

63 Véanse, al respecto, la SAP de Madrid 567/2019; STSJ Comunidad Valenciana 5/2019; SAP Madrid 423/2019; y STSJ Cataluña 123/2019. Y, en cuanto a la estimación acerca de las ganancias ilícitas, según el Informe "Transnational Crime and the Developing Word" de la Fundación Global Financial Integrity (2017), la trata transnacional de personas con fines de explotación sexual generaría, específicamente, unos beneficios de 21.800 dólares anuales por cada víctima.

64 CASTELLVÍ MONSERRAT, C.: "Decomisar sin castigar", en Indret, $\mathrm{n}^{\circ} 1,2019$, p. 6. 


\subsection{La pena de multa proporcional}

En virtud del artículo 50 del Código Penal español, la pena de multa consiste en la imposición al condenado de una sanción pecuniaria, que será, salvo que se disponga otra cosa, por el sistema de días-multa. El artículo 52, por su parte, determina que cuando el Código así lo determine, la multa se establecerá en proporción al daño causado, el valor del objeto del delito o el beneficio reportado por el mismo.

Por lo tanto, el Código Penal español, como muchos otros de nuestro entorno ${ }^{65}$, contempla dos modalidades distintas de pena de multa, cuyos fundamentos y ámbitos de aplicación resultan absolutamente dispares: la multa por cuotas (también denominada "sistema días-multa"), que se aplicará de manera preferente, y la multa proporcional.

Como se ha acreditado por parte de la investigación criminológica, la pena privativa de libertad de corta duración no sólo es ineficaz, sino también considerablemente perturbadora. Las penas privativas de libertad de corta duración no sirven para la resocialización, contaminan al penado, y colapsan y sobrecargan el aparato estatal de ejecución de penas $^{66}$.

65 Francia, Grecia, Suecia o Finlandia son ejemplos de países que combinan los dos modelos según la naturaleza de los delitos: el de días-multa, de forma generalizada, y un sistema de multa proporcional al beneficio para evitar la escasa cuantía que se alcanza con el primero. Al respecto, MAPELLI CAFFARENA, B.: Las consecuencias jurídicas del delito, Madrid, 2011, p. 222. Por el contrario, otros países han optado por una de estas dos modalidades. Así, por ejemplo, en Reino Unido se derogó en 1993 el sistema días multa, quedando únicamente la multa proporcional en su ordenamiento jurídico-penal; y, por el contrario, en Alemania, solo se impone la multa por cuotas. Véase, al respecto, SALINERO, S. / MORALES, A.M. / CASTRO, A.: "Análisis comparado y crítico de las alternativas a las penas privativas de libertad. La experiencia española, inglesa y alemana”, en Política Criminal, n² 24, 2017, pp. 786-864.

66 GRACIA MARTÍN, L.: "La pena de multa", en GRACIA MARTÍN, L. (Coord.), Tratado de las consecuencias jurídicas del delito, Valencia, 2006, p. 175. 
Pues bien, la principal función político-criminal que desempeña la pena de multa por cuotas es la de operar como sustitutivo de este tipo de penas. El también llamado "modelo escandinavo" se utiliza en la medida de lo posible como sustitutivo de las penas privativas de libertad de corta duración ${ }^{67}$.

GRACIA MARTÍN detalla las ventajas de este sistema: en primer lugar, que tiene mayor efecto especial preventivo porque la posible repercusión psicológica que la multa causa al culpable resulta tanto mayor cuanto más proporcionada se encuentre a sus haberes; $y$, en segundo lugar, que genera menos casos de impago, al no haberse impuesto al culpable, en atención a su situación patrimonial, una sanción desproporcionada. En cambio, su eficacia disuasoria en términos de prevención general es muy cuestionable ${ }^{68}$.

El mantenimiento de la multa proporcional, en cambio, se quiere justificar con base en dos argumentos: por un lado, que es una respuesta para aquellos casos en que infracciones administrativas (idénticas cualitativamente al delito, aunque de menor gravedad) se hallan ya sancionadas con multas que superan los límites máximos de las multas por cuotas; y, por otro lado, por razones retributivas y de prevención general en relación con delitos caracterizados por la obtención de grandes beneficios económicos mediante una conducta fraudulenta y respecto de los cuales la multa por cuotas puede resultar excesivamente benigna y por ello ineficaz como instrumento intimidatorio ${ }^{69}$.

67 MARTÍNEZ-BUJÁN PÉREZ, C.: "Regulación de la pena de multa en el Código Penal Español de 1995 (los días-multas y la multa proporcional, con referencia a la responsabilidad personal subsidiaria en caso de impago)", en Estudios penales y criminológicos, n 20, 1997, p. 231.

68 GRACIA MARTÍN, L.: "La pena de multa", ob. cit., 2006, pp. 181-182.

69 MAPELLI CAFFARENA, B.: Las consecuencias jurídicas del delito, ob. cit., p. 235; SÁNCHEZ GARCÍA DE LA PAZ, I.: "Artículo 50" y "Artículo 52", en GÓMEZ TOMILLO, M. (Dir.), Comentarios 
Pero, destaca GRACIA MARTÍN que ello «resulta perturbador y contradictorio». En relación con delitos que proporcionan al autor elevadas ganancias o que producen enormes perjuicios, considera este autor que la gravedad del hecho apunta a que la pena indicada debe ser la privativa de libertad y no la de multa. Y si está indicada la acumulación de una multa para algunos de tales delitos, entonces debería poder aplicarse mediante el sistema días-multa, aunque para ello deba suprimirse el límite máximo de la cuantía de la cuota diaria actualmente prevista en el Código penal. El autor sostiene también que el perjuicio causado constituye un elemento del desvalor del resultado que determinará siempre, por ello, una mayor gravedad de lo injusto, por lo que debería ser tenido en cuenta en la determinación del número de cuotas. Finalmente, el beneficio obtenido con el delito, a su juicio, debería ser neutralizado mediante la institución del decomiso $^{70}$.

\section{A este tipo de críticas, MARTÍNEZ-BUJÁN PÉREZ} responde que la pena de multa proporcional resulta conveniente sobre todo para ser aplicada a determinadas clases de delitos que generan relevantes beneficios y que son difíciles de recuperar por otros medios. Y es que, efectivamente, teniendo en cuenta la legislación penal en vigor, solo la pena de multa proporcional parece tener la utilidad político-criminal de desincentivar a la delincuencia con finalidades lucrativas ${ }^{71}$.

prácticos al Código Penal. Parte General, Aranzadi, Pamplona, 2015, p. 576; CARDENAL MONTRAVETA, S.: "La pena de multa prevista para los delitos relacionados con el consumo ilegal de drogas", en Indret, $\mathrm{n}^{\circ} 1,2020$, p. 180.

70 GRACIA MARTÍN, L.: "La pena de multa", en GRACIA MARTÍN, L. (Coord.). Lecciones de consecuencias jurídicas del delito, Valencia, 2016, p. 99.

71 MARTÍNEZ-BUJÁN PÉREZ, C.: "Regulación de la pena de multa en el Código Penal Español de 1995 (los días-multas y la multa proporcional, con referencia a la responsabilidad personal subsidiaria en caso de impago)", ob. cit., p. 252. 
Como se expone, acertadamente, en la STS 279/2018, de 12 de junio, esta sanción se contempla «en delitos de funcionarios públicos y en delitos socioeconómicos, caracterizados estos por su capacidad para generar cuantiosos e incluso enormes beneficios; donde además, la multa patrimonial, en todos estos ilícitos no se contempla como pena única, salvo para muy concretas figuras atenuadas, sino que acompaña de forma conjunta al menos a la pena de prisión, con relativa frecuencia de naturaleza grave. Es decir, la multa proporcional, desde una perspectiva de prevención general, complementa habitualmente a la pena de prisión, encaminada a procurar que el delito no sea rentable; pero no sólo priva del valor del objeto del delito o el beneficio reportado, sino dos, tres, cuatro o hasta seis veces esa cifra, de modo que con frecuencia supone un desapoderamiento de todo o gran parte del patrimonio del autor».

Efectivamente, en los 30 preceptos del Código Penal español en los que actualmente se prevé una pena de multa proporcional para las personas físicas ${ }^{72}$ se contienen delitos en los que subyace un contenido económico, sea porque su comisión lleva aparejada la causación de un importante

72 En particular, el Código Penal español prevé la multa proporcional para las personas físicas en los siguientes delitos: daños informáticos (arts. 264.2 y 264 bis.2); delitos relativos al mercado y los consumidores (arts. 284 y 285); corrupción en los negocios (arts. 286 bis y 286 ter); delitos societarios (arts. 291 y 292); blanqueo de capitales (art. 301); financiación ilegal de partidos políticos (art. 304 bis); delitos contra la Hacienda Pública (arts. 305, 305 bis y 306); delitos contra la Seguridad Social (arts. 307, 307 bis, 307 ter y 308); delitos sobre la ordenación del territorio y el urbanismo (art. 319); tráfico de drogas (arts. 368, 369, 369 bis y 370); tráfico de precursores (art. 371); falsificación de monedas (art. 386 ); aprovechamiento por particular del secreto o información privilegiada que obtuviera de un funcionario público (art. 418); tráfico de influencias (arts. 428 y 429); uso de información privilegiada por funcionario (art. 442); cohecho de funcionario de la Corte Penal Internacional (art. 471 bis.7); y financiación del terrorismo (art. 576). Además, en las leyes especiales también aparece la multa proporcional (por ejemplo, en el art. 3.1 de la Ley de Contrabando). 
perjuicio para terceros, sea porque produce la obtención de un relevante beneficio para el delincuente ${ }^{73}$.

En cualquier caso, debe tenerse en cuenta que la eficacia preventiva y la legitimidad de la pena de multa dependen de que su cuantía se determine teniendo en cuenta la situación económica del condenado (y no solo la gravedad del hecho) de manera que, en relación con los autores de un mismo delito, el contenido aflictivo de dicha pena, el sacrificio que comporta, sea siempre el mismo o, por lo menos, no dependa injustamente de su situación económica ${ }^{74}$.

\section{Los delitos transnacionales en España}

En las anteriores páginas hemos tratado de analizar el fenómeno de la delincuencia transnacional desde un punto de vista criminológico, centrándonos, sobre todo, en los beneficios que genera. Por el contrario, este epígrafe se ocupa de la regulación del fenómeno en el ordenamiento jurídicopenal español.

España ha ratificado tanto el Convenio de Palermo ${ }^{75}$, como los protocolos adicionales contra el tráfico ilícito de migrantes ${ }^{76}$, contra la trata de personas ${ }^{77}$ y contra la fabricación y el tráfico ilícitos de $\operatorname{armas}^{78}$. Asimismo, ha ratificado la Convención de Viena ${ }^{79}$.

73 MARTÍNEZ-BUJÁN PÉREZ, C.: "Regulación de la pena de multa en el Código Penal Español de 1995 (los días-multas y la multa proporcional, con referencia a la responsabilidad personal subsidiaria en caso de impago)", ob. cit., p. 250.

74 CARDENAL MONTRAVETA, S.: "La pena de multa prevista para los delitos relacionados con el consumo ilegal de drogas", ob. cit., p. 182.

75 Publicado en el BOE de 29 de septiembre de 2003.

76 Publicado en el BOE de 10 de diciembre de 2003.

77 Publicado en el BOE de 11 de diciembre de 2003.

78 Publicado en el BOE de 23 de marzo de 2007.

79 Publicado en el BOE de 10 de noviembre de 1990. 
Todos estos son instrumentos de base para luchar globalmente contra la delincuencia transnacional. Pero lo cierto es que España no ha regulado específicamente el crimen organizado transnacional. No existe, como por ejemplo en Italia, una ley que transponga qué se entiende por delito transnacional ${ }^{80}$. En definitiva, la delincuencia transnacional, a pesar de haber ganado de forma progresiva una mayor atención durante las últimas décadas, carece de un conjunto de normas que la aborde de manera integral, con las divergencias injustificadas que esta carencia conlleva ${ }^{81}$. Sí se han insertado, en cambio, en el Código Penal, mediante la Ley Orgánica 5/2010, de 22 de junio, las nociones de "grupo delictivo organizado" y "grupo estructurado" exigidas en la Decisión Marco 2008/841/JAI. Así, los artículos 570 bis y 570 ter regulan, respectivamente, la organización criminal y el grupo criminal ${ }^{82}$.

Seguidamente, se examinan por separado los tipos penales que sancionan en España a las personas físicas que cometan los delitos transnacionales objeto del presente trabajo, así como su aplicación por parte de los tribunales. En particular, por lo que se refiere a la jurisprudencia, se han analizado las sentencias condenatorias dictadas en el año 2019 por parte del Tribunal Supremo, las Audiencias Provinciales y los Tribunales Superiores de Justicia.

\subsection{El delito de tráfico de drogas}

A pesar de que la Convención de Palermo y sus Protocolos no se refieren al delito de tráfico de drogas, la Convención de Viena ya había puesto de relieve el hecho de que los «rendimientos financieros y grandes fortunas» derivadas del

80 Ley núm. 146, de 16 de marzo de 2006.

81 PÉREZ CEPEDA, A.I.: “Existe un sistema penal transnacional?”, ob. cit., p. 235.

82 ZÚÑIGA RODRÍGUEZ, L.: "El concepto de criminalidad organizada transnacional: problemas y propuestas”, ob. cit., p. 170. 
tráfico de drogas permiten «a las organizaciones delictivas transnacionales invadir, contaminar y corromper las estructuras de la Administración pública, las actividades comerciales y financieras lícitas, y la sociedad a todos sus niveles». Consciente de esto, el alcance de la Convención se circunscribe a los supuestos de tráfico ilícito de estupefacientes y sustancias psicotrópicas que tengan una dimensión internacional (art. 2). Igualmente, se acuerda tener en cuenta «la participación en el delito de un grupo delictivo organizado del que el delincuente forme parte», como circunstancia que infiere especial gravedad a los hechos (art. 3.5.a). Y, finalmente, en lo que aquí nos importa, la Convención de Viena prevé, explícitamente, la posibilidad de aplicar sanciones pecuniarias y el decomiso frente a los delitos de tráfico ilícito de drogas (art. 3.4).

El Código Penal español tipifica el delito de tráfico de drogas junto con los delitos contra la salud pública (Capítulo III del Título XVII, referido a los delitos contra la seguridad colectiva, del Libro Segundo). En concreto, dedica los artículos 368 a 371 a la tipificación de la conducta y la previsión de circunstancias agravantes ${ }^{83}$. Dentro de estas circunstancias, se prevé la realización de la conducta típica «por quienes pertenezcan a una organización delictiva», diferenciando penológicamente según se trate de mera pertenencia a la organización o de jefes, encargados o administradores de ella, así como de la peligrosidad para la salud de la sustancia objeto de tráfico (art. 369 bis). De este modo, se prevé la imposición de penas de prisión de nueve a doce años y multa del tanto al cuádruplo del valor de la droga cuando las sustancias y productos causen grave daño a la salud y, en los demás casos, penas de prisión de cuatro años y seis meses a diez años junto con la misma multa cuando el autor pertenezca a la

83 Solo el párrafo segundo del artículo 368 contempla una modalidad atenuada, potestativa, "en atención a la escasa entidad del hecho y a las circunstancias personales del culpable». 
organización; y las penas superiores en grado, cuando se trate de jefes, encargados o administradores. Junto a esta previsión, el artículo $370.3^{\circ}$ prevé la imposición de la pena superior en uno o dos grados de la prevista para el tipo básico (penas de prisión de tres a seis años y multa del tanto al triplo del valor de la droga objeto del delito si se tratare de sustancias o productos que causen grave daño a la salud, y de prisión de uno a tres años y multa del tanto al duplo en los demás casos), cuando los hechos «fuesen de extrema gravedad». El propio precepto se ocupa de aclarar cuándo se debe considerar esto y, entre las posibilidades que ofrece, alude a que «se trate de redes internacionales dedicadas a este tipo de actividades».

Así pues, en el delito de tráfico de drogas la realización de los hechos por parte de una organización criminal y el carácter transnacional de la actividad constituyen modalidades agravadas. Sin embargo, la mera adquisición y/o entrada de la droga desde el extranjero o su traslado a través de varios países no satisface el carácter transnacional del art. $370.3^{\circ}$ del Código Penal. Debe tenerse en cuenta que se alude a «redes internacionales» ${ }^{84}$. Conforme a la Circular $n^{0} 2 / 2005$, de 31 de marzo, sobre la reforma del Código Penal en relación con los delitos de tráfico ilegal de drogas, con esta circunstancia se comprenden tanto los supuestos en los que el autor está integrado en la red delictiva internacional como aquellos en los que simplemente se aprovecha de su entramado.

84 Sobre los problemas interpretativos que se desprenden del art. $370.3^{\circ}$, ampliamente MANJÓN-CABEZA OLMEDA, A.: "3.4. Extrema gravedad. Las distintas modalidades de la extrema gravedad", en ÁLVAREZ GARCÍA, F.J. (Dir.), ÁLVAREZ GARCÍA, F.J./MANJÓN-CABEZA OLMEDA, A. (Coords.), El delito de tráfico de drogas, Valencia, 2009, pp. 253-255. Resulta de interés, también, la Circular $n^{\circ} 3 / 2011$, de de 11 de octubre, sobre la reforma del Código Penal efectuada por la Ley Orgánica 5/2010, de 22 de junio, en relación con los delitos de tráfico ilegal de drogas y precursores, en relación a los problemas concursales de los subtipos agravados de los arts. 368, 369, 369 bis y $370 \mathrm{del}$ Código penal. 
De este modo, para que concurra la circunstancia, lo único que se exige es bien una relación entre varias organizaciones criminales autónomas entre sí, pertenecientes a distintos Estados, cuya finalidad sea el tráfico internacional de drogas; o bien, una macroorganización internacional con estructuras organizadas y distribuidas en varios territorios ${ }^{85}$.

Tal y como se ha indicado ya, la sanción prevista será privativa de libertad y pecuniaria. Se contempla la pena de multa proporcional, con mayor efecto disuasorio para estos delitos. Adicionalmente, en el artículo 374 del Código Penal se establece el decomiso de «las drogas tóxicas, estupefacientes o sustancias psicotrópicas, los equipos, materiales y sustancias a que se refiere el artículo 371, así como los bienes, medios, instrumentos y ganancias». Se cumple así con la recomendación del artículo 3.4 de la Convención de Viena. Además, siguiendo los criterios advertidos por RODRÍGUEZ GARCÍA, el decomiso se justifica en el delito de tráfico de drogas porque su comisión supone la creación de un mercado paralelo al legal, donde las sustancias o al menos los principios activos que las componen pueden ser objeto de transacción con fines terapéuticos o de investigación, cumpliendo con las exigencias legales; concurre un incuestionable ánimo de lucro, los beneficios derivados del mercado ilícito son sustancialmente superiores a los eventuales costes que pueden producirse si se interceptase alguna operación; y, finalmente, el tráfico de drogas provoca alarma social.

Yendo a su aplicación jurisprudencial, sorprende que a lo largo del año 2019 no hayamos encontrado ninguna sentencia condenatoria por la concurrencia del art. $370.3^{\circ}$ en la variante de que se trate de redes internacionales, si tenemos

85 Véase MÉNDEZ RODRÍGUEZ, C.: "Los delitos de pertenencia a organización criminal y a grupo criminal y el delito de tráfico de drogas cometido por persona que pertenece a una organización delictiva. Crónica de un conflicto normativo anunciado y análisis jurisprudencial", en Estudios Penales y Criminológicos, vol. XXXIV, 2014, p. 547. 
en cuenta la situación geoestratégica que ocupa España y los lazos culturales existentes con los principales países productores $^{86}$. Sí se han dictado dos sentencias condenatorias, aplicando el art. 369 bis ${ }^{87}$. Pero en ellas, asombrosamente, no se alude ni a la responsabilidad civil ni al decomiso de ganancias, a pesar de los datos de beneficios económicos que se atribuyen a este fenómeno y que lo convierten en el mercado criminal más lucrativo a nivel mundial. Por un lado, en la SAN 10/2019 el decomiso se limita a los bienes utilizados para la preparación o ejecución del delito. Por otro lado, en la SAN 17/2019, aunque sí se alude al decomiso del dinero, en realidad no se indica que se trate del beneficio derivado del delito, por lo que podría ser dinero previsto para la adquisición de materiales o derivado de otra acción.

\subsection{El delito de tráfico de armas}

El tráfico ilícito de armas es uno de los fenómenos que, como se ha advertido en las páginas anteriores, genera mayores beneficios en su dimensión transnacional (hasta 3.000 millones de euros al año mundialmente). Con la finalidad de «promover, facilitar y reforzar la cooperación entre los Estados Parte con el propósito de prevenir, combatir y erradicar la fabricación y el tráfico ilícitos de armas de fuego, sus piezas y componentes y municiones» se aprobó el Protocolo contra la fabricación y el tráfico ilícitos de armas de fuego, sus piezas y componentes y municiones ${ }^{88}$. En él se insta a los Estados Parte a sancionar penalmente tres comportamientos: la fabricación, el tráfico y la alteración ilícitas de armas de fuego en un contexto transnacional. Asimismo, se exige que la tipificación contemple la tentativa de comisión, junto con la participación en calidad de cómplice, y la organización,

86 Orden PCI/161/2019, de 21 de febrero, por la que se publica el Acuerdo del Consejo de Seguridad Nacional, por el que se aprueba la Estrategia Nacional contra el Crimen Organizado y la Delincuencia Grave.

87 SAN 10/2019 y SAN 17/2019.

88 Artículo 2. 
dirección, ayuda, incitación, facilitación o asesoramiento para la comisión de algunos de estos delitos ${ }^{89}$.

El Código Penal vigente reserva el Capítulo V a la tenencia, tráfico y depósito de armas, municiones y explosi$\operatorname{vos}^{90}$, dentro del Título XXII del Libro Segundo, dedicado a los Delitos contra el orden público. En realidad, la tipificación del tráfico ilícito de armas supone una novedad del texto punitivo de 1995 (arts. 566 y 567). En el Código Penal anterior solo se perseguía penalmente la tenencia o el depósito, por lo que el tráfico se suma a ellas, creando un totum revolutum

89 El artículo 5 establece lo siguiente: «Cada Estado Parte adoptará las medidas legislativas o de otra índole que sean necesarias para tipificar como delito las siguientes conductas, cuando se cometan intencionalmente: a) La fabricación ilícita de armas de fuego, sus piezas y componentes y municiones; b) El tráfico ilícito de armas de fuego, sus piezas y componentes y municiones; c) La falsificación o la obliteración, supresión o alteración ilícitas de la(s) marca(s) de un arma de fuego requerida(s) de conformidad con el artículo 8 del presente Protocolo. Cada Estado Parte adoptará asimismo las medidas legislativas y de otra índole que sean necesarias para tipificar como delito las siguientes conductas: a) Con sujeción a los conceptos básicos de su ordenamiento jurídico, la tentativa de comisión de un delito tipificado con arreglo al párrafo 1 del presente artículo o la participación en él como cómplice; y b) La organización, dirección, ayuda, incitación, facilitación o asesoramiento para la comisión de un delito tipificado con arreglo al párrafo 1 del presente artículo».

90 Esto es así desde la reforma operada mediante la Ley Orgánica 5/2010, de 22 de junio. Hasta el momento, el Capítulo V tenía por rúbrica De la tenencia, tráfico y depósitos de armas, municiones o explosivos y de los delitos de terrorismo. Si bien, dicho Capítulo V se dividía en dos Secciones y se distinguía el terrorismo de los delitos relacionados con la tenencia, tráfico y depósito de armas, con la reforma del Código Penal realizada a través de la Ley Orgánica 1/2015, de 30 de marzo, se modifican los artículos 566 y 567, incorporando junto a las armas o municiones de guerra o de armas químicas o biológicas o de minas antipersonas o municiones de racimo, las armas nucleares o radiológicas. Sobre los antecedentes y la ubicación sistemática del delito de tráfico ilícito de armas, véanse HAVA GARCÍA, E.: El control penal de las armas. Análisis del Capítulo V del Título XXII del Código Penal, Valencia, 2019, pp. 65-81; y DE LA CUESTA, AGUADO, P. M., Delitos de tráfico ilegal de personas, objetos o mercancías, Valencia, 2014, pp. 21-32. 
que se ha complicado aún más con las sucesivas reformas penales, tal y como advierte HAVA GARCÍA ${ }^{91}$

Siendo esto así, en la actualidad, el apartado 1 del artículo 566 sanciona a quienes «fabriquen, comercialicen o establezcan depósitos de armas o municiones no autorizadas por las leyes o la autoridad competente», condicionando la pena en atención al tipo de armas -si son de guerra, químicas, biológicas, nucleares o radiológicas o de minas antipersonas o municiones de racimo, o si son armas de fuego reglamentadas o sus municiones- y en función de la participación en los hechos -promotores y organizadores, o meros cooperadores en su formación- $\left(\operatorname{art} .566 .1 .1^{\circ} \text { y } 2^{\circ}\right)^{92}$. Y en el número $3^{\circ}$ del mismo apartado 1 se alude al «tráfico de armas o municiones de guerra o de defensa, o de armas químicas, biológicas, nucleares o radiológicas o de minas antipersonas o municiones en racimo». De manera que no se sanciona penalmente el tráfico de armas de fuego ni se alude al elemento transnacional, a pesar de las exigencias contenidas en el Protocolo contra la fabricación y el tráfico ilícito de armas de fuego, sus piezas y componentes y municiones ${ }^{93}$.

91 HAVA GARCÍA, E.: El control penal de las armas. Análisis del Capítulo $V$ del Título XXII del Código Penal, ob. cit., p. 135. Así, la autora considera que «se mezclan sin orden ni concierto las diferentes conductas típicas»y, con las reformas posteriores se desarrolla «una regulación penal enormemente casuística que, como suele suceder en tales circunstancias, además de dificultar en general la labor del intérprete crea determinadas lagunas de punición a todas luces indeseables».

92 Artículo $566.1 \mathrm{CP}$ : «1. ${ }^{\circ} \mathrm{Si}$ se trata de armas o municiones de guerra o de armas químicas, biológicas, nucleares o radiológicas o de minas antipersonas o municiones en racimo, con la pena de prisión de cinco a diez años los promotores y organizadores, y con la de prisión de tres a cinco años los que hayan cooperado a su formación. $2{ }^{\circ}$ Si se trata de armas de fuego reglamentadas o municiones para las mismas, con la pena de prisión de dos a cuatro años los promotores y organizadores, y con la de prisión de seis meses a dos años los que hayan cooperado a su formación».

93 La Unión Europea advierte, precisamente, de los inconvenientes que esta falta de transposición del contenido del Protocolo contra la fabricación 
Esta regulación exige un esfuerzo interpretativo por el que se delimite el ámbito de aplicación de la modalidad de tráfico respecto de la modalidad de comercialización de armas $^{94}$. Cabría esperar que el artículo 567 del Código Penal arrojase algo de luz porque en él se contienen algunas interpretaciones auténticas. Sin embargo, en la práctica se mezclan las modalidades y se considera que «la fabricación, la comercialización o la tenencia de cualquiera» de las armas de guerra (apartado 1) o de las armas de fuego reglamentadas (apartado 3) constituyen un depósito de armas. Por lo tanto, la comercialización se configura como una categoría de depósito, caracterizado por comprender «tanto la adquisición como la enajenación» (art. 567.1 in fine), mientras que sobre el tráfico, en sentido estricto, no se establece ninguna referencia adicional aclaratoria.

Siendo esto así, se antoja necesario realizar una interpretación sistemática. Estamos con HAVA GARCÍA cuando entiende que la tipificación del tráfico supone un adelantamiento de las barreras de protección, en relación con la

y el tráfico ilícito de armas de fuego, sus piezas y componentes y municiones por parte de los Estados Miembros puede tener para las operaciones conjuntas transfronterizas, como las entregas controladas. Véase, al respecto, la Comunicación de la Comisión al Parlamento Europeo, al Consejo, al Comité Económico y Social Europeo, y al Comité de Regiones. Plan de Acción de la UE sobre el Tráfico de armas de fuego 2020-2025, de 24 de julio de 2020 [COM(2020) 608 final].

94 Esta diferencia, sin embargo, no aparece en la Directiva (UE) 2017/853 del Parlamento Europeo y del Consejo, de 17 de mayo de 2017 por la que se modifica la Directiva 91/477/CEE del Consejo sobre el control de la adquisición y tenencia de armas. En la nueva redacción del artículo 1.1.12) se define el "tráfico ilícito" como «la adquisición, venta, entrega, circulación o transferencia de armas de fuego, sus componentes esenciales o municiones desde o a través del territorio de un Estado miembro al de otro Estado miembro si cualquiera de los Estados miembros interesados no lo autoriza conforme a lo dispuesto en la presente Directiva o si las armas de fuego, componentes esenciales o municiones no han sido marcados de conformidad con el artículo 4». De este modo, el tráfico ilícito comprende tanto los actos preparatorios como los de ejecución. 
comercialización ${ }^{95}$. El tráfico se asocia a actos preparatorios como «circulación, traslado, entrega, introducción en el territorio de dicha mercancía» y por eso su punición se reserva a determinadas armas. Por su parte, la comercialización, tal y como establece la Ley, persigue la adquisición y la enajenación, por lo que en ella tienen cabida solo actos puramente ejecutivos ${ }^{96}$.

Tampoco resulta especialmente clara la pena a imponer ante el tráfico de armas. El problema está en que el apartado $3^{\circ}$ del artículo 566.1 del Código Penal, donde se sanciona el tráfico de armas o municiones de guerra o de defensa, o de armas químicas, biológicas, nucleares o radiológicas o de minas antipersonas o municiones en racimo, no establece un marco penal, sino que se limita a indicar: "Con las mismas penas [...], en sus respectivos casos». Se mantiene, pues, la diferencia penológica establecida en los apartados $1^{\circ}$ y $2^{\circ}$ entre «promotores y organizadores» y cooperadores en su formación pero no se aclara si las penas serán las previstas en un apartado o en otro. Parece que lo razonable sería haber integrado la punición del tráfico en un segundo párrafo del apartado $2^{\circ}$ si se quisiera mantener la misma pena. Por ende, a priori, se podría considerar que la remisión se realiza al apartado $1^{\circ}$. No obstante, debemos tener en cuenta que

95 HAVA GARCÍA, E.: El control penal de las armas. Análisis del Capítulo $V$ del Título XXII del Código Penal, ob. cit., pp. 147-154

96 Resulta de interés, también, DE LA CUESTA, AGUADO, P. M.: Delitos de tráfico ilegal de personas, objetos o mercancias, Valencia, 2014, p. 82, donde dice «el verbo "traficar" sustituye a la retahíla de verbos típicos a la que recurren los que hemos denominado como preceptoscascada para describir todo el proceso mercantil objeto de la intervención (o tutela) penal. Así, conductas como vender, poner en circulación, expender, importar o exportar, trasladar o transportar, poseer para la venta o tráfico, almacenar, etc., pueden ser considerados como actos aislados de un proceso sintéticamente descrito por el verbo "traficar"; proceso mercantil cuyo control parece ser la razón la intervención penal, como he reiterado».

97 Esta acción se prevé junto con fabricar y establecer depósitos, si bien no resultan de interés en este momento de nuestro estudio. 
las armas objeto de la acción de traficar coinciden prácticamente con las citadas en el apartado apartado $1^{\circ}$ donde la acción típica es comercializar ${ }^{97}$, salvo por la incorporación al catálogo del apartado $3^{\circ}$ de las armas de defensa. Aceptar que esta es la remisión supone equiparar la pena de los actos preparatorios con los actos de ejecución. De haber querido hacer esto, hubiera sido mejor indicar directamente en el citado apartado $1^{\circ}$ este propósito. Bajo nuestro punto de vista, la interpretación dada a las acciones de tráfico y de comercialización justifican una diferencia penológica sustancial en la medida en que las primeras son actos preparatorios de las segundas. Sin embargo, esto tampoco se especifica claramente en el precepto y, al menos hasta donde hemos llegado, no ha sido objeto de análisis y/o discusión por parte de la doctrina.

Si se admite lo anterior, en el caso de la comercialización, se prevé una pena de prisión de cinco a diez años para los promotores y organizadores, y de tres a cinco años para los que hayan cooperado a su formación. Mientras que en el caso del tráfico de estas mismas armas, junto con las de defensa, o municiones se prevé una pena de prisión de dos a cuatro años de promotores y organizadores, y de seis meses a dos años los que hayan cooperado a su formación. En ninguno de los casos se contempla de forma alternativa ni acumulativa la pena de multa ${ }^{98}$, ni se establece el decomiso específico. Obviamente, el juzgador podrá decretarlo en la Sentencia condenatoria, conforme al artículo 127 del Código Penal. De facto, así viene ocurriendo en la jurisprudencia de manera constante y así lo encontramos en las sentencias dictadas en el año $2019^{99}$. Esto tiene sentido ya que el delito

98 Sí se establecen multas administrativas de hasta 600.000 euros para sancionar, por ejemplo, la fabricación, reparación, almacenamiento y comercio de armas de fuego prohibidas o de armas de guerra sin la adecuada habilitación, cuando no constituyan delito, en aplicación del artículo 155 del Reglamento de Armas.

99 SAP Madrid 76/2019; SAP Cuenca 8/2019; STS 137/2019; SAP Cádiz 94/2019; SAP Málaga 197/2019. 
de tráfico de armas cumple con los denominadores comunes de los delitos que justifican la existencia del decomiso: se produce en un contexto de mercado paralelo a otro legal, regulado, la acción está revestida de un evidente ánimo de lucro y provoca alarma social, así como efectos negativos en la integridad institucional y el desarrollo económico, político y social de los países ${ }^{100}$.

Por el contrario, la responsabilidad civil derivada del delito no se reconoce en ninguna de las resoluciones judiciales analizadas, a pesar de haberse podido establecer en virtud del artículo 109 y ss. ${ }^{101}$.

Finalmente, se debe advertir que, de todas las sentencias condenatorias dictadas en el año 2019, solo una presenta carácter transnacional (SAP Madrid 76/2019) ${ }^{102}$, pero no se aprecia la participación de una organización criminal en el relato de hechos probados. Por lo tanto, únicamente se sanciona la conducta de un sujeto que actúa de forma autónoma. Esto sorprende si atendemos a las declaraciones contenidas en la Orden PCI/161/2019, de 21 de febrero, por la que se publica el Acuerdo del Consejo de Seguridad Nacional, por el que se aprueba la Estrategia Nacional contra el Crimen Organizado y la Delincuencia Grave: «[1]as falsificaciones documentales de todo tipo junto al tráfico ilegal de armas son actividades conexas o vinculadas al crimen organizado y la

100 RODRÍGUEZ GARCÍA, N.: "En la búsqueda de un sistema penal más eficaz en el combate a la corrupción: expectativas depositadas en el decomiso", ob. cit., pp. 3 y ss.

101 En la SAP Cuenca 8/2019 y en la SAP Cádiz 94/2019 se reconoce, pero en relación con otros delitos cometidos por los autores.

$102 \mathrm{El}$ acusado (y posteriormente condenado) «con ánimo de ilícito enriquecimiento, adquirió tanto de particulares como de armerías de Estados Unidos, Bélgica, Austria y Alemania entre otras, un elevado número de municiones, armas inutilizadas, cañones y otras piezas fundamentales, para proceder a la rehabilitación, ensamblaje y fabricación ilícita de armas de fuego completas a base de sus diferentes piezas y destinarlas al tráfico ilícito» (hechos probados I. Antecedentes de hecho, Segundo. SAP Madrid 76/2019). 
delincuencia grave que perfeccionan los mismos, por lo que deben ser debidamente tratados». Sin embargo, la tendencia jurisprudencial podría variar en las resoluciones judiciales que se dicten en los próximos años si atendemos a las últimas macrooperaciones efectuadas por las Fuerzas y Cuerpos de Seguridad en el año $2020^{103}$.

\subsection{El tráfico de personas}

Como ya se ha indicado, con la expresión "tráfico de personas" se alude a dos fenómenos criminales muy distintos: la trata de personas y el tráfico ilícito de migrantes. En el ordenamiento jurídico-penal español se tipifican de manera diferenciada desde la aprobación de la Ley Orgánica 5/2010, de 22 de junio. De este modo, se reserva el artículo 318 bis al tráfico ilícito de migrantes y el 177 bis a la trata de personas $^{104}$. Ambos han sido modificados a través de la Ley Orgánica 1/2015, de 30 de marzo, con el objeto de adaptar su descripción a la normativa europea, tal y como se reconoce en la Exposición de Motivos ${ }^{105}$.

\subsubsection{El delito de tráfico ilícito de migrantes}

En el artículo 3 del Protocolo contra el tráfico ilícito de migrantes por tierra, mar y aire se establece que "tráfico ilícito de migrantes" será «la facilitación de la entrada ilegal de una persona en un Estado Parte del cual dicha persona no sea

103 Véanse, al respecto, las notas 40 y 41.

104 El delito de tráfico ilícito de migrantes del artículo 318 bis del Código Penal se incorporó por primera vez a la legislación penal mediante la Ley Orgánica 4/2000, de 11 de enero, sobre derechos y libertades de los extranjeros en España y su integración social, y fue modificado por la Ley Orgánica 11/2003, de 29 de septiembre, de medidas concretas en materia de seguridad ciudadana, violencia doméstica e integración social de los extranjeros.

105 La Exposición de Motivos XXV determina lo siguiente: «Directiva 2002/90/CE; y, de otra, para ajustar las penas conforme a lo dispuesto en la Decisión Marco 2002/946/JAI, [...] La reforma culmina también la transposición efectiva de la Directiva 2009/52/CE, [...]». 
nacional o residente permanente con el fin de obtener, directa $\mathrm{o}$ indirectamente, un beneficio financiero u otro beneficio de orden material». Y en el artículo 6 se determina qué conductas, en torno al tráfico ilícito, deben sancionarse penalmente por los Estados Parte «cuando se cometan intencionalmente y con el fin de obtener, directa o indirectamente, un beneficio económico $u$ otro beneficio de orden material: a) El tráfico ilícito de migrantes; b) Cuando se cometan con el fin de posibilitar el tráfico ilícito de migrantes: i) La creación de un documento de viaje o de identidad falso; ii) La facilitación, el suministro o la posesión de tal documento. c) La habilitación de una persona que no sea nacional o residente permanente para permanecer en el Estado interesado sin haber cumplido los requisitos para permanecer legalmente en ese Estado, recurriendo a los medios mencionados en el apartado b) del presente párrafo o a cualquier otro medio ilegal». Si bien, como recuerda DAUNIS RODRÍGUEZ, estas conductas se circunscriben a aquellas situaciones que tengan un "carácter transnacional y entrañen la participación de un grupo delictivo organizado» ${ }^{106}$.

La tipificación de estos hechos la encontramos en el art. 318 bis 1 in fine en relación con el apartado 3 a). En el art. 318 bis, con la reforma de 2015, se ha eliminado la referencia a "tráfico ilícito" pero se describen directamente las modalidades delictivas. Así, en su primer apartado, se sanciona a quien «intencionadamente ayude a una persona que no sea nacional de un Estado miembro de la Unión Europea a entrar en territorio español o a transitar a través del mismo de un modo que vulnere la legislación sobre entrada o tránsito de extranjeros», previendo una agravación de la pena cuando se realice con ánimo de lucro (in fine) ${ }^{107}$. Esta

106 DAUNIS RODRÍGUEZ, A.: "Sobre la urgente necesidad de una tipificación autónoma e independiente de la trata de personas", en Indret, $\mathrm{n}^{\circ}$ 1, 2010, p. 7.

107 Esto significa que se sanciona penalmente también a quien ayuda sin ánimo de lucro, lo cual ha sido muy criticado por la doctrina. 
previsión estaría contraviniendo lo dispuesto en el Protocolo contra el tráfico ilícito de migrantes por tierra, mar y aire, que contempla el «beneficio financiero u otro beneficio material» como elemento esencial. Para solventar este inconveniente, quizás convendría limitar la sanción penal al tráfico ilícito de migrantes cometido con ánimo de lucro y castigar administrativamente las conductas cometidas sin él.

En el apartado 3 se contemplan las modalidades agravadas del apartado primero en general, es decir, tanto de la ayuda con ánimo de lucro como de la ayuda sin él, para entrar o transitar. La agravación de la pena es sustancial. Si en el apartado 1 se prevé una pena de multa de tres a doce meses o prisión de tres meses a un año, imponiéndose en su mitad superior cuando se actúe con ánimo de lucro, cuando los hechos se comentan en el seno de una organización criminal que se dedicare a estas actividades o cuando se hubiera puesto en peligro la vida de las personas objeto de la infracción o se hubiera creado el peligro de causación de lesiones graves, se contempla una pena de prisión de cuatro a ocho años, descartando la imposición de una pena de multa, como ocurría en el tipo básico. Al respecto, resulta sorprendente la equiparación penológica si los hechos transcurren con o sin ánimo de lucro. Si bien es cierto que, en los supuestos en los que intervenga una organización criminal siempre va a producirse ánimo de lucro, no es así en los casos en los que se haya puesto en peligro la vida o la integridad física y, sin embargo, la pena prevista es la misma. Entendemos inadmisible la equiparación. No hacer una distinción nos lleva al absurdo

La Directiva 2002/90/CE exige que los Estados prevean sanciones frente a estas conductas pero no que estas deban ser penales. Véanse CONDEPUMPIDO TOURÓN, C./BARJA DE QUIROGA, J.: "Artículo 318 bis del Código Penal", en CONDE-PUMPIDO TOURÓN, C., (Dir.), Comentarios al Código Penal. Vol. II, Bosch, Barcelona, 2007, p. 2439; y SÁNCHEZ LÁZARO, F. G.: "El nuevo delito de tráfico ilegal de personas", en LAURENZO COPELLO, P. (Coord.), Inmigración y Derecho Penal. Bases para un debate, Tirant lo Blanch, Valencia, 2002, p. 290. 
de que por ejemplo, se condene a seis años de prisión, aplicando el artículo 318 bis 1 in fine y 3 b) del Código Penal a un sujeto que organizó y dirigió un viaje de quince personas en una embarcación neumática sin chalecos ni bengalas, a cambio de mil euros por persona ${ }^{108}$, mientras se impone una pena de cinco años y seis meses de prisión (solo seis meses menos que en el caso anterior) a un sujeto que transportó camuflado en su vehículo a un migrante indocumentado, sin que conste que mediara precio ni que lo hubiera hecho en otras ocasiones ${ }^{109}$. En cualquier caso, y volviendo a nuestro objeto de estudio, el carácter transnacional del delito de tráfico ilícito de migrantes en el ordenamiento español se prevé en la propia redacción del tipo mientras que la realización de los hechos en el seno de una organización criminal constituye una modalidad agravada.

En lo que a las consecuencias jurídico-penales se refiere, como ya hemos advertido, en el tipo básico, agravado por el ánimo de lucro, se prevé de manera alternativa una pena de multa o una pena de prisión, si bien, en la modalidad agravada por la realización de los hechos en el seno de una organización criminal, se incrementa la pena de prisión y desaparece la opción de aplicar la multa. Esto tiene sentido porque la multa del tipo básico es una multa por día y no una multa proporcional. De este modo, el desvalor de la acción por realizarse en una estructura organizada dedicada a este fenómeno, supone un mayor riesgo para el bien jurídico y por lo tanto una mayor posibilidad de lesión. La multa por día no resulta en absoluto disuasoria en este tipo de delitos. Distinto hubiera sido si se contemplara la imposición de una pena proporcional al beneficio obtenido. Finalmente, no se

108 Así ocurre en la SAP Málaga 4/2020. Si bien, la misma sección $7^{\text {a }}$ de la Audiencia Provincial de Málaga en Sentencia 7/2019, había reconocido que «existen ciertos medios para el transporte que incorporan generalmente este elemento de peligro, entre ellos, los traslados en frágiles embarcaciones (pateras, cayucos) generadores por sí el peligro concreto».

109 Como es el caso de la SAP Murcia 6/2020. 
regula en torno al delito de tráfico de migrantes el decomiso específico de los beneficios que se deriven. No obstante, igual que en el caso del tráfico de armas, es posible aplicar la normativa general del artículo 127 y siguientes del Código Penal. Téngase en cuenta que, el delito de tráfico de migrantes cumple también con los denominadores comunes que estamos considerando para los delitos en los que se justifica esta respuesta: existe un mercado legal, en este caso, la posibilidad de moverse de un país a otro dentro de los márgenes legales; quienes realizan la acción se mueven por el ánimo de lucro (recuérdese que el fenómeno genera entre 4.600 y 6.000 millones de euros al año a nivel mundial), si bien es cierto que en el delito de tráfico de migrantes este ánimo de lucro no siempre existe ${ }^{110}$; del tráfico ilegal se deriva alarma social, en este caso concreto se asocia en numerosas ocasiones a delincuencia; y, finalmente, afecta a la integridad institucional, y el desarrollo económico, político y social de los países ${ }^{111}$.

Señalado lo anterior, corresponde detenernos en la aplicación jurisprudencial de esta figura delictiva a lo largo del año 2019. Conforme al rastreo realizado, se han dictado siete sentencias condenatorias en aplicación del artículo 318 bis $^{112}$, de las cuales, en ninguna se considera que los hechos se hayan cometido en el seno de una organización que se dedique a estas actividades. Por lo tanto, no se aplica la letra a) del apartado 3 del artículo 318 bis del Código Penal. Esto resulta sorprendente porque, tal y como subraya la propia

110 Sobre la tipificación de esta conducta sin ánimo de lucro, nos hemos ocupado recientemente en TAPIA BALLESTEROS, P., "Tratamiento jurídico penal de los beneficios económicos derivados del tráfico de personas y de la migración irregular, clandestina o ilegal", en Revista Paradigma, Ribeirão Preto-SP, a. XXV, v. 29, n 1, 2020, pp. 43 y ss.

111 RODRÍGUEZ GARCÍA, N.: "En la búsqueda de un sistema penal más eficaz en el combate a la corrupción: expectativas depositadas en el decomiso", ob. cit., pp. 3 y ss.

112 SAP de Málaga 7/2019; SAP de Murcia 130/2019; SAP de Cádiz 58/2019; SAP de Coruña 298/2019; SAP de Las Palmas 241/2019; SAP de Vizcaya 54/2019; SAP de Almería 314/2019. 
INTERPOL, «se estima que más del 90\% de los migrantes que llegan a la Unión Europea lo hacen a través de miembros de una red delictiva ${ }^{113}$. Además, en el relato de hechos probados de dos de ellas, sí se hace referencia a la participación de otras personas e, incluso, podría deducirse una estructura organizativa. Si bien, ni siquiera se solicita la consideración de la modalidad agravada. Así, en la SAP de Murcia (Sección $2^{\text {a }}$ ) 130/2019, de 30 de abril, se hace referencia de forma explícita a que el acusado actúa "en virtud del encargo expreso de la persona organizadora de la travesía desde la costa africana» y en la SAP de Almería (Sección 3 $3^{a}$ ) 314/2019, de 18 de septiembre, se indica que los dos acusados actúan «de acuerdo y en connivencia con las personas organizadoras del viaje».

No obstante lo anterior, con el objeto de poder, al menos, analizar las consecuencias jurídicas que se establecen, nos encontramos con que en ninguna se decreta el decomiso de los beneficios derivados de la acción delictiva y solo en dos se determina el decomiso de la embarcación utilizada para realizar el traslado hacia España ${ }^{114}$. Y esto con independencia de que se acredite en el relato de hechos probados que la actuación se realiza con ánimo de lucro.

Lo anterior supone que en las dos sentencias donde se identifica el beneficio específico derivado del delito ${ }^{115}$, dicho beneficio sigue formando parte del patrimonio de los condenados. $\mathrm{Y}$ en las seis sentencias restantes ni siquiera se ha

113 Véase, al respecto, el Informe disponible en: http://www.interpol.int/es/ Delitos/Trafico-ilicito-de-migrantes/Trafico-ilicito-de-migrantes-problematica (última consulta: 04/01/2021).

114 SAP de Cádiz 58/2019 y SAP de Almería 314/2019. Si bien, en la SAP de Las Palmas 241/2019 se determina el decomiso de los efectos intervenidos en poder de los acusados, pero no por el delito de tráfico de personas sino porque concurre también un delito de tráfico de drogas y es en relación a este al que se decreta el decomiso.

115 SAP Coruña 298/2019; SAP Vizcaya 54/2019. 
hecho el esfuerzo de determinar cuál fue la cantidad específica entregada para conseguir la ayuda en el acceso o tránsito ${ }^{116}$.

En lo que a los instrumentos de ejecución se refiere, no existe un criterio, o al menos no lo hemos identificado, que justifique el decreto de su decomiso. En cinco de los supuestos la ayuda se realizó a través de una embarcación ${ }^{117}$, pero solo se decretó el decomiso en tres de las sentencias ${ }^{118}$, uno de los cuales estaba vinculado a un delito de tráfico de drogas ${ }^{119}$.

\subsubsection{El delito de trata de personas}

Como ya se ha indicado, la trata de personas se tipifica de forma autónoma en el artículo 177 bis del Código Penal desde la reforma operada por la Ley Orgánica 5/2010 Con la incorporación de este nuevo tipo al Código penal se sanciona la conducta de quien «empleando violencia, intimidación o engaño, o abusando de una situación de superioridad o de necesidad o de vulnerabilidad de la víctima nacional o extranjera, o mediante la entrega o recepción de pagos o beneficios para lograr el consentimiento de la persona que poseyera el control sobre la víctima, la captare, transportare, trasladare, acogiere, o recibiere, incluido el intercambio o transferencia de control sobre esas personas», siempre y cuando se actúe conforme a alguna de las finalidades

116 En la SAP Almería 314/2019 ni siquiera se alude al ánimo de lucro, aunque se desprende del relato de hechos probados: son dos sujetos que patronean una embarcación para introducir en España a 49 inmigrantes. Resulta difícil creer se realizara sin obtener un beneficio económico a cambio. Sin embargo, esto no afecta en la determinación de la pena porque concurre la modalidad agravada del apartado 3.b).

117 SAP Málaga 7/2019; SAP Almería 314/2019; SAP Murcia 130/2019; SAP Las Palmas 241/2019; SAP Cádiz 58/2019.

118 SAP Almería 314/2019; SAP Las Palmas 241/2019; SAP Cádiz 58/2019. 119 SAP Las Palmas 241/2019.

120 Hasta ese momento, solo se sancionaba penalmente la trata de personas cuando tenía carácter transnacional y la finalidad era de explotación sexual, en el apartado 2 del artículo 318 bis. 
tasadas en el propio precepto ${ }^{121}$. Y se configura como modalidad agravada el hecho de que «el culpable perteneciera a una organización o asociación de más de dos personas, incluso de carácter transitorio, que se dedicase a la realización de tales actividades» (apartado 6).

De este modo, el delito de trata de personas se corresponde con las exigencias del Protocolo para prevenir, reprimir y sancionar la trata de personas, especialmente mujeres y niños, en cuyo artículo 3 a) se define la trata de personas como « la captación, el transporte, el traslado, la acogida o la recepción de personas, recurriendo a la amenaza o al uso de la fuerza u otras formas de coacción, al rapto, al fraude, al engaño, al abuso de poder o de una situación de vulnerabilidad o a la concesión o recepción de pagos o beneficios para obtener el consentimiento de una persona que tenga autoridad sobre otra, con fines de explotación. Esa explotación incluirá, como mínimo, la explotación de la prostitución ajena u otras formas de explotación sexual, los trabajos o servicios forzados, la esclavitud o las prácticas análogas a la esclavitud, la servidumbre o la extracción de órganos»y, conforme al artículo 4 del mismo, los hechos presenten un carácter transnacional y «entrañen la participación de un grupo delictivo organizado».

Cumpliéndose estas dos exigencias, que serán comunes al delito de tráfico ilícito de migrantes del artículo 318 bis y de la trata de seres humanos del artículo 177 bis, en la medida en que este último se desarrolle en el ámbito transnacional, las diferencias entre ambos serían, como ya se ha indicado, que, la trata de seres humanos implica necesariamente

121 Esta definición sigue lo establecido en el artículo 2 de la Directiva 2011/36/UE del Parlamento Europeo y del Consejo, de 5 de abril de 2011, relativa a la prevención y lucha contra la trata de seres humanos y a la protección de las víctimas y por la que se sustituye la Decisión Marco 2002/629/JAI del Consejo. Véase, al respecto, MOYA GUILLEM, C.: La trata de seres humanos con fines de extracción de órganos. Análisis criminológico y jurídico-penal, Tirant lo Blanch, Valencia, 2020, pp. 74-87. 
la ausencia de voluntad por parte del sujeto que es objeto del traslado y la finalidad de explotación. Recuérdese que, en el delito previsto en el artículo 318 bis el migrante desea llegar al Estado Parte y el ánimo de lucro se relaciona con la travesía, no con una acción posterior. Sin embargo, en la trata de seres humanos el migrante es trasladado sin su consentimiento o mediante un consentimiento viciado, y dicho traslado tiene una finalidad lucrativa posterior.

Centrándonos en la pena prevista, será de ocho años y un día a doce años de prisión, junto con la inhabilitación especial para profesión, oficio, industria o comercio por el mismo tiempo, cuando los hechos se produzcan en el seno de una organización criminal; de diez a doce años de prisión si, además, se hubiera puesto en peligro la vida o la integridad física o psíquica de la víctima o esta fuera especialmente vulnerable por razón de su enfermedad, estado gestacional, discapacidad o situación personal, o sea menor de edad; y una pena de prisión de doce años y un día a dieciocho años, en el caso en que el sujeto haya actuado prevaliéndose de su condición de autoridad, agente de esta o funcionario público. De nuevo, no se hace ninguna referencia específica al decomiso de los beneficios obtenidos ni se contempla la aplicación de una pena de multa proporcional, de forma adicional a la pena de prisión.

Obviamente, igual que en los delitos de tráfico de drogas, tráfico ilícito de armas y tráfico ilícito de migrantes, el decomiso puede, y debe, establecerse en la sentencia condenatoria. Este fenómeno implica la existencia de un mercado paralelo a uno lícito, ánimo de lucro, alarma social y afecta a la integridad institucional, y al desarrollo económico, político y social ${ }^{122}$. Empero, como veremos a continuación, su previsión no es habitual.

122 RODRÍGUEZ GARCÍA, N.: "En la búsqueda de un sistema penal más eficaz en el combate a la corrupción: expectativas depositadas en el decomiso", ob. cit., pp. 3 y ss. 
Del análisis jurisprudencial realizado de las resoluciones del año 2019, se han identificado quince sentencias condenatorias por el artículo 177 bis del Código Penal ${ }^{123}$. Entre ellas, diez contemplan la concurrencia del artículo 318 bis, por lo que se reconoce el carácter transnacional ${ }^{124}$. Si bien, esto no significa que en las restantes no exista este fenómeno. De facto, en todas ellas las víctimas se trasladan desde su país de origen (en concreto, Nigeria o Rumanía) hasta España de manera irregular sin su consentimiento o estando este viciado por engaño ${ }^{125}$. Por otro lado, paradójicamente, de todas ellas solo en tres se considera que quienes realizan la conducta delictiva pertenecen a una organización dedicada a estos fines ${ }^{126}$.

Centrándonos en la respuesta penal prevista en estas resoluciones jurisprudenciales, nos encontramos con que solo en la SAP de Barcelona 398/2019 se prevé la imposición de una pena de multa a uno de los condenados, si bien de escasa entidad (multa de seis meses con cuota diaria de 4 euros) y, como se ha adelantado, de naturaleza no proporcional. Por su parte, únicamente en tres Sentencias se procedió al decomiso ${ }^{127}$ y ni siquiera se alude directamente al beneficio

123 SAP Almería 451/2019; SAP Madrid 732/2019; SAP Madrid 83/2019; STS 554/2019; STSJ Cataluña 123/2019; SAP Madrid 498/2019; SAP de Madrid 567/2019; SAN 13/2019; SAP Barcelona 398/2019; STS 396/2019; SAP Madrid 423/2019; SAP Baleares 346/2019; SAP Las Palmas 128/2019; SAP Barcelona 200/2019; STS 77/2019; y la STSJ Comunidad Valenciana 5/2019.

124 SAP Almería 451/2019; SAP Madrid 83/2019; STS 554/2019; SAP de Madrid 567/2019; SAP Barcelona 398/2019; STS 396/2019; SAP Baleares 346/2019; SAP Barcelona 200/2019; STS 77/2019; y la STSJ Comunidad Valenciana 5/2019.

$125 \mathrm{Se}$ valora la posibilidad de un concurso medial entre el 318 bis y el 177 bis en la SAP de Madrid 423/2019 y en la SAP de Madrid 732/2019, si bien se descarta finalmente.

126 STS 77/2019; STS 554/2019; SAN 1/2019.

127 SAP de Madrid 567/2019; SAN 13/2019; y STSJ de la Comunidad Valenciana 5/2019. 
derivado del delito. Las sentencias se limitan a decretar el decomiso de los efectos y del dinero intervenidos. Sí resulta habitual la determinación de una indemnización a las víctimas. En once de las resoluciones analizadas se establece la obligación de abonar, en concepto de responsabilidad civil, cantidades que oscilan entre los 5000 y los 60.000 euros $^{128}$

Con todo, teniendo en cuenta que por cada víctima los beneficios generados ascienden a más de 20.000 euros al año ${ }^{129}$, no parece que con estos fallos se vaya a disuadir a quienes pretenden cometer estas prácticas ilegales para lucrarse económicamente.

\section{Conclusiones}

Ante el riesgo que representa toda delincuencia transnacional que se aprovecha de las posibilidades técnicas globales, las normas nacionales cada vez son menos eficaces.

La delincuencia transnacional genera ganancias ilícitas muy superiores a las de la delincuencia doméstica y también es sustancialmente más peligrosa para los intereses tutelados por los ordenamientos jurídicos al afectar, no solo a los bienes protegidos en las figuras delictivas que la sancionan penalmente (contra los que también atenta y, por lo general, en mayor medida al potenciarse exponencialmente el número de afectados), sino también a la economía, la gobernabilidad y el correcto funcionamiento de las instituciones públicas ${ }^{130}$.

128 No se contempla la indemnización a las víctimas en las Sentencias: SAP de Barcelona 398/2019; STSJ de la Comunidad Valenciana 5/2019; SAN 1/2019; SAN 13/2019.

129 Según el Informe "Transnational Crime and the Developing Word" de la Fundación Global Financial Integrity (2017), la trata transnacional de personas con fines de explotación sexual generaría, específicamente, unos beneficios de 21.800 dólares anuales por cada víctima.

130 Como se explica en la Orden PCI/161/2019, de 21 de febrero, por la que se publica el Acuerdo del Consejo de Seguridad Nacional, por el que se aprueba la Estrategia Nacional contra el Crimen Organizado y la Delincuencia 
Esta es la razón por la que sorprende que el elemento transnacional solo permita agravar la pena prevista en el tipo básico de tráfico de drogas en virtud del artículo $370.3^{\circ}$ del Código Penal (aunque su aplicación haya sido escasa en las resoluciones judiciales que han sido objeto de análisis), pero, en cambio, no se contemple para los delitos de trata de personas y tráfico de $\operatorname{armas}^{131}$.

En otro orden de cosas, considerando los enormes beneficios que se obtienen a través de la delincuencia transnacional, también resulta asombroso que no se aprovechen adecuadamente los recursos de los que dispone el ordenamiento en el Libro I del Código penal. Desde los más relevantes organismos nacionales e internacionales solo se insiste en el empleo de la figura del decomiso. Sin embargo, entendemos que la multa proporcional también debería preverse entre las sanciones penales a la delincuencia transnacional, puesto que, según hemos podido advertir mediante el análisis jurisprudencial efectuado, ni el decomiso de ganancias ni la responsabilidad civil derivada del delito consiguen privar a quienes cometen los ilícitos penales examinados de sus ilícitas ganancias.

La pena de multa proporcional es una medida sumamente atractiva para desincentivar económicamente la

Grave, «desestabiliza y perturba la economía, creando una suerte de mercados paralelos, un sector "informal" que no respeta ni leyes ni regulaciones, una superposición entre la economía legal y la economía ilícita que puede llegar incluso a dinamizar artificialmente algunos sectores de modo que reducen los índices de productividad, se rebaja o elimina la competitividad y desincentiva la actividad empresarial. Utiliza la corrupción y otras formas de presión e influencia, aspirando, en casos, a consolidar posiciones de poder político y actuar como un grupo de presión para intentar controlar distintas instituciones».

131 Como hemos explicado en el texto, el tráfico ilícito de migrantes requiere que se dé el elemento transnacional en el tipo básico. En otro orden de cosas, se ha previsto la reincidencia internacional en el delito de trata de seres humanos y en el de tráfico de drogas (art. 375), pero no en el delito de tráfico ilícito de migrantes ni en el de tráfico de armas. 
delincuencia con finalidades lucrativas y, consecuentemente, un recurso muy eficaz en términos de prevención general, si se añade al decomiso de ganancias y a la responsabilidad civil.

A mayor abundamiento, si se contemplase la pena de multa proporcional para las personas físicas en los delitos transnacionales, estaríamos alineados con los Estados de nuestro entorno, lo que permitiría un sentimiento común de justicia y de valoración de los bienes jurídicos que merecen ser protegidos, y permitiría la adaptación del espacio común europeo a las nuevas tipologías criminales de carácter transnacional ${ }^{132}$. Como sostiene MAPELLI CAFFARENA, mientras que se presente un panorama diverso los sistemas de penas seguirán teniendo graves dificultades para hacer ágiles los traslados de condenados, la euro-orden o el reconocimiento mutuo de sentencias penales de otros países y, consiguientemente, los delincuentes alcanzarán la impunidad mediante estrategias de deslocalización ${ }^{133}$.

132 Como establece el Documento de Antecedentes Enfoques investigativos y procesales para combatir el tráfico ilícito de armas de fuego y las formas conexas de delincuencia dentro de las jurisdicciones y entre ellas, presentado en la Conferencia de las Partes en la Convención de las Naciones Unidas contra la Delincuencia organizada transnacional celebrada el 28 de enero de 2020, la armonización de los marcos jurídicos entre los países es, a este respecto, otra condición importante para establecer definiciones, criterios y normas comunes que permitan a los Estados cooperar más eficazmente entre sí y evitar el riesgo de que los delincuentes y los terroristas se aprovechen de las lagunas legales y la discrepancia entre legislaciones. A título de ejemplo, tras los atentados terroristas de 2014 y 2015 en Europa, la Unión Europea detectó importantes lagunas en su marco jurídico y en el de sus Estados miembros en lo que respectaba a las normas de desactivación y la reglamentación de la tenencia de determinadas armas (como las pistolas de gas y de alarma) que permitían a los terroristas adquirir armas legales que puedan ser reactivadas ilegalmente o transformadas en armas de fuego real. En respuesta a ese examen legislativo, la Directiva 91/477/CEE del Consejo, de 18 de junio de 1991, relativa al control de la adquisición y tenencia de armas, fue modificada por la Directiva (UE) 2017/853 del Parlamento Europeo y del Consejo, de 17 de mayo de 2017.

133 MAPELLI CAFFARENA, B.: Las consecuencias jurídicas del delito, ob. cit., p. 44. 
Sentado lo anterior, sostenemos la necesidad de una reforma de los delitos de tráfico de armas y de trata de personas, para que, siguiendo el modelo incriminador del delito de tráfico de drogas, por un lado, contemplen una agravación específica que se aplique cuando concurra el elemento transnacional y, por otro lado, incluyan la pena de multa proporcional como sanción para las personas físicas. Esta última previsión, igualmente, debería contemplarse en el delito de tráfico ilícito de migrantes, que solo debería castigar a quienes realizan las conductas típicas en él previstas con ánimo de lucro.

\section{Bibliografía}

AGUADO CORREA, T.: "Cinco años después de las reformas del decomiso: does crime still pay?", en BERDUGO GÓMEZ DE LA TORRE, I./ RODRÍGUEZ GARCÍA, N., (Eds.), Decomiso y recuperación de activos crime doesn't pay, Valencia, 2020, pp. 55-82.

AGUADO CORREA, T.: "Decomiso de los productos de la delincuencia organizada. Garantizar que el delito no resulte provechoso", en Revista Electrónica de Ciencia Penal y Criminología, $\mathrm{n}^{\circ}$ 15-05, 2013, pp. 1-27.

ALASTUEY DOBÓN, C., "Artículo 110", en GÓMEZ TOMILlO, M. (dir.), Comentarios Prácticos al Código Penal. Tomo I. Parte General. Artículos 1-137, Thomson Reuters Aranzadi, Navarra, 2015, págs. 899-901

BLANCO CORDERO, I: "El debate en España sobre la necesidad de castigar penalmente el enriquecimiento ilícito de empleados públicos”, en Revista electrónica de ciencia penal y criminológica, 19, 2017, pp. 1-35.

CASANUEVA SANZ, I./ GIL NOBAJAS, $\mathrm{M}^{\mathrm{a}}$ S./ ARMAZA ARMAZA, E.J.: "La decisión marco 2005/212: Antecedente y origen de las últimas reformas del comiso como consecuencia accesoria”, en Estudios de Deusto: revista de la Universidad de Deusto, vol. 66, 
$\mathrm{n}^{\mathrm{o}} 2$ 2, 2018, pp. 397-434. https://doi.org/10.18543/ed66(2)-2018pp397-434

CARDENAL MONTRAVETA, S.: "La pena de multa prevista para los delitos relacionados con el consumo ilegal de drogas", en Indret, $\mathrm{n}^{\circ}$ 1, 2020, 176-200.

CARRILLO DEL TESO, A.E.: Decomiso y recuperación de activos en el sistema penal español, Tirant lo Blanch, Valencia, 2018.

CARRILLO DEL TESO, A.E.: "La Directiva 2014/42/UE sobre el embargo y el decomiso de los instrumentos y del producto del delito en la UE: decomiso ampliado y presunción de inocencia", en Revista de Estudios Europeos, $\mathrm{n}^{\circ}$ extraordinario monográfico, 1, 2017, pp. 20-32.

CASTELLVÍ MONSERRAT, C.: "Decomisar sin castigar", en Indret, $\mathrm{n}^{\circ}$ 1, 2019, 1-66.

CONDE-PUMPIDO TOURÓN, C./BARJA DE QUIROGA, J.: "Artículo 318 bis del Código Penal", en CONDE-PUMPIDO TOURÓN, C., (Dir.), Comentarios al Código Penal. Vol. II, Barcelona, 2007, pp.

DAUNIS RODRÍGUEZ, A.: "Sobre la urgente necesidad de una tipificación autónoma e independiente de la trata de personas", en Indret, $\mathrm{n}^{\circ}$ 1, 2010, pp. 1-44

DE LA CUESTA AGUADO, P.M.: Delitos de tráfico ilegal de personas, objetos o mercancías, Valencia, 2014, pp. 117.

DEL-CARPIO-DELGADO, J.: "El paradigma del volumen del patrimonio criminal y de su blanqueo", en DELCARPIO-DELGADO, J. (Dir.), Criminalidad en un mundo global, Valencia, 2020, pp. 397-435.

DÍAZ CABIALE, J.A.: "El decomiso tras las reformas del Código Penal y la Ley de Enjuiciamiento Criminal de 2015", en Revista electrónica de ciencia penal y criminología, ${ }^{\circ} 18,2016$, pp. 1-70.

DURÁN SILVA, C.: "Las presunciones legales iuris tantum en la figura del decomiso", en Revista General de Derecho Procesal, ${ }^{\circ}$ 48, 2019, pp. 1-28. 
GORJÓN BARRANCO, M ${ }^{\mathrm{a}}$ C.: "El comiso ampliado como paradigma del moderno Derecho Penal", en Revista Penal, no 38, 2016, pp. 127-146.

GRACIA MARTÍN, L.: "La pena de multa", en Gracia Martín, L. (Coord.), Tratado de las consecuencias jurídicas del delito, Valencia, 2006, 171-204.

GRACIA MARTÍN, L.: "La pena de multa" y "Consecuencias jurídicas no penales derivadas de la comisión del delito (I)", en GRACIA MARTÍN, L. (Coord.), Lecciones de consecuencias jurídicas del delito, Valencia, 2016, 91-107 y 232-239.

GRANADOS MUÑOZ, C.: "El decomiso de los bienes, efectos o ganancias procedentes del delito", en Revista Jurídica de Castilla y León, $\mathrm{n}^{\circ}$ 48, mayo 2019, pp. 87-127.

HAVA GARCÍA, E.: El control penal de las armas. Análisis del Capítulo V del Título XXII del Código Penal, Valencia, 2019.

HORTAL IBARRA, J.C., "La naturaleza jurídica de la responsabilidad civil ex delicto: o cómo "resolver" la cuadratura del círculo", en Indret, $\mathrm{n}^{\circ}$ 4, octubre, 2014, págs. 1-30.

LORENTE PABLO, E.: "La investigación patrimonial: aspectos prácticos del decomiso y de la recuperación de activos", en BERDUGO GÓMEZ DE LA TORRE, I./ RODRÍGUEZ GARCÍA, N., (Eds.), Decomiso y recuperación de activos crime doesn't pay, Valencia, 2020, pp. 839-870.

MANJÓN-CABEZA OLMEDA, A.: "3.4. Extrema gravedad. Las distintas modalidades de la extrema gravedad", en ÁlVAREZ GARCÍA, F.J. (Dir.) ÁLVAREZ GARCÍA, F.J./MANJÓN-CABEZA OLMEDA, A. (Coords.), El delito de tráfico de drogas, Valencia, 2009.

MAPELLI CAFFARENA, B.: Las consecuencias jurídicas del delito, Madrid, 2011.

MARTÍNEZ-BUJÁN PÉREZ, C.: "Regulación de la pena de multa en el Código Penal Español de 1995 (los 
días-multas y la multa proporcional, con referencia a la responsabilidad personal subsidiaria en caso de impago)", en Estudios penales y criminológicos, $\mathrm{n}^{\circ} 20$, 1997, 225-286.

MÉNDEZ RODRÍGUEZ, C.: "Los delitos de pertenencia a organización criminal y a grupo criminal y el delito de tráfico de drogas cometido por persona que pertenece a una organización delictiva. Crónica de un conflicto normativo anunciado y análisis jurisprudencial", en Estudios Penales y Criminológicos, vol. XXXIV, 2014, pp. 511-560.

MOYA GUILLEM, C.: La trata de seres humanos con fines de extracción de órganos. Análisis criminológico y jurídico-penal, Valencia, 2020.

NEIRA PENA, A.M.: "Decomiso: entre garantismo y eficacia. Las presunciones legales sobre el origen ilícito de los bienes", en BERDUGO GÓMEZ DE LA TORRE, I./ RODRÍGUEZ GARCÍA, N., (Eds.), Decomiso y recuperación de activos crime doesn't pay, Valencia, 2020, pp. 89-122.

OLASOLO ALONSO, H.: "¿Se debe recurrir a los mecanismos de respuesta del Derecho internacional penal para hacer frente a los delitos transnacionales?", en PÉREZ CEPEDA, A.I. (Dir.), Política criminal ante el reto de la delincuencia transnacional, Valencia, 2016, p. 119.

PÉREZ ALONSO, E.: Tráfico de personas e inmigración clandestina, Tirant lo Blanch, Valencia, 2008, pp. 155-156.

PÉREZ CEPEDA, A.I.: “¿Existe un sistema penal transnacional?", en PÉREZ CEPEDA, A.I. (Dir.), Politica criminal ante el reto de la delincuencia transnacional, Valencia, 2016, p. 235.

PÉREZ CEPEDA, A.I.: Globalización, tráfico internacional ilícito de personas y derecho penal, Granada, 2004.

PUEYO RODERO, J.A.: "La nueva regulación del comiso en el Código Penal", en Cuadernos penales José María Lidón, $\mathrm{n}^{\circ}$ 15, la ejecución de las penas, 2019, pp. 109-129. 
QUINTERO OLIVARES, G.: "La globalización y el Derecho penal: un cajón de sastre conceptual", en GALÁN MUÑOZ, A. (Coord.), Globalización y lucha contra las nuevas formas de criminalidad transnacional, Valencia, 2019, p. 21.

QUINTERO OLIVARES, G.: "El comiso tras la reforma del Código penal (LO 1/2015, de 30 de marzo)", en Cuadernos penales José María Lidón, $\mathrm{n}^{\circ}$ 12, 2016, pp. 41- 62.

RODRÍGUEZ GARCÍA, N.: "El decomiso en el sistema penal español: análisis de contexto y lineamientos para una mejor intelección", en BERDUGO GÓMEZ DE LA TORRE, I./ RODRÍGUEZ GARCÍA, N., (Eds.), Decomiso y recuperación de activos crime doesn't pay, Valencia, 2020, pp. 19-54.

RODRÍGUEZ GARCÍA, N.: "En la búsqueda de un sistema penal más eficaz en el combate a la corrupción: expectativas depositadas en el decomiso", en Revista Internacional Transparencia e Integridad, $\mathrm{n}^{\circ} 1$, mayoagosto, 2016, pp. 1-7.

ROIG TORRES, M.: "La regulación del comiso. El modelo alemán y la reciente reforma española", en Estudios Penales y Criminológicos, vol XXXVI, 2016, pp. 199-279.

RUIZ DÍAZ, L.J.: "Diez años de la adopción de la Decisión marco 2008/841/JAI, del Consejo relativa a la lucha contra la delincuencia organizada. Luces y sombras de un legado más que dudoso", Revista de Derecho comunitario europeo, $\mathrm{n}^{\circ} 61,2018$, pp. 1091-1119. https:// doi.org/10.18042/cepc/rdce.61.08

SALINERO, S. / MORALES, A.M. / CASTRO, A.; "Análisis comparado y crítico de las alternativas a las penas privativas de libertad. La experiencia española, inglesa y alemana", en Política Criminal, n 24, 2017, 786-864. https://doi.org/10.4067/s0718-33992017000200786

SÁNCHEZ GARCÍA DE LA PAZ, I.: "Artículo 50" y “Artículo 52", en GÓMEZ TOMILLO, M. (Dir.), 
Comentarios prácticos al Código Penal. Parte General, Pamplona, 2015, 567-577.

SÁNCHEZ LÁZARO, F.G.: "El nuevo delito de tráfico ilegal de personas", en LAURENZO COPELLO, P. (Coord.), Inmigración y Derecho Penal. Bases para un debate, Tirant lo Blanch, Valencia, 2002, pp. 287-308.

TAPIA BALLESTEROS, P.: "Tratamiento jurídico penal de los beneficios económicos derivados del tráfico de personas y de la migración irregular, clandestina o ilegal”, en Revista Paradigma, Ribeirão Preto-SP, a. XXV, v. 29, nº 1, 2020, pp. 36-54.

ZÚÑIGA RODRÍGUEZ, L.: "El concepto de criminalidad organizada transnacional: problemas y propuestas", en PÉREZ CEPEDA, A.I. (Dir.), Política criminal ante el reto de la delincuencia transnacional, Valencia, 2016, p. 170.

\section{Referencias jurisprudenciales}

Sentencia del Tribunal Supremo (Sala de lo Penal, Sección $1^{\text {a) }} 77 / 2019$, de 12 de febrero.

Sentencia del Tribunal Supremo (Sala de lo Penal, Sección $1^{\text {a) }}$ 137/2019, de 12 de marzo.

Sentencia del Tribunal Supremo (Sala de lo Penal, Sección $1^{\text {a) }} 396 / 2019$, de 24 de julio.

Sentencia del Tribunal Supremo (Sala de lo Penal, Sección $1^{\text {a) }} 554 / 2019$, de 13 de noviembre.

Sentencia de la Audiencia Nacional (Sala de lo Penal, Sección $1^{\text {a) }}$ 10/2019, 5 de abril.

Sentencia de la Audiencia Nacional (Sala de lo Penal, Sección $4^{a}$ ) 17/2019, de 23 julio.

Sentencia de la Audiencia Nacional (Sala de Apelación) 13/2019, de 31 de julio.

Sentencia del Tribunal Superior de Justicia de Cataluña (Sala de lo Civil y Penal, Sección 1 ${ }^{\text {a) }}$ 123/2019, de 18 de octubre. 
Sentencia del Tribunal Superior de Justicia de la Comunidad Valenciana (Sala de lo Civil y Penal, Sección $1^{\text {a }}$ ) 5/2019, de 18 de enero.

Sentencia de la Audiencia Provincial de Almería (Sección $3^{\mathrm{a}}$ ) 314/2019, de 18 de septiembre.

Sentencia de la Audiencia Provincial de Almería (Sección 3a) 451/2019, de 20 de diciembre.

Sentencia de la Audiencia Provincial de Barcelona (Sección $5^{\text {a) }}$ 200/2019, de 20 de marzo.

Sentencia de la Audiencia Provincial de Barcelona (Sección $8^{a}$ ) 398/2019, de 31 de julio.

Sentencia de la Audiencia Provincial de Baleares (Sección 2a 346/2019, de 4 de junio.

Sentencia de la Audiencia Provincial de Cádiz (Sección 4a) 94/2019, de 5 de abril.

Sentencia de la Audiencia Provincial de Cádiz (Sección 6a 58/2019, de 28 de junio.

Sentencia de la Audiencia Provincial de Coruña (Sección 2aa) 298/2019, de 8 de julio.

Sentencia de la Audiencia Provincial de Cuenca (Sección 1aa) 8/2019, de 13 de marzo.

Sentencia de la Audiencia Provincial de Las Palmas (Sección $2^{\text {a }) ~ 128 / 2019, ~ d e ~} 4$ de abril.

Sentencia de la Audiencia Provincial de Las Palmas (Sección $2^{\text {a) }}$ 241/2019, de 12 de julio.

Sentencia de la Audiencia Provincial de Madrid (Sección $7^{\mathrm{a}}$ ) 76/2019, de 4 de febrero.

Sentencia de la Audiencia Provincial de Madrid (Sección $1^{\mathrm{a}}$ ) 498/2019, de 30 de septiembre.

Sentencia de la Audiencia Provincial de Madrid (Sección $3^{\mathrm{a}}$ ) 732/2019, de 18 de diciembre.

Sentencia de la Audiencia Provincial de Madrid (Sección 5a) 83/2019, de 11 de diciembre.

Sentencia de la Audiencia Provincial de Madrid (Sección 23ª 567/2019, de 18 de septiembre.

Sentencia de la Audiencia Provincial de Madrid (Sección 15ª) 
423/2019, de 24 de junio.

Sentencia de la Audiencia Provincial de Málaga (Sección 3 $3^{\mathrm{a}}$ ) 197/2019, de 31 de mayo.

Sentencia de la Audiencia Provincial de Málaga (Sección 7 ${ }^{\mathrm{a}}$, Melilla), 7/2019, de 14 de enero.

Sentencia de la Audiencia Provincial de Murcia (Sección 2a 130/2019, de 30 de abril.

Sentencia de la Audiencia Provincial de Murcia (Sección 5a) 6/2020, de 17 de enero.

Sentencia de la Audiencia Provincial de Vizcaya (Sección 1ª) 54/2019, de 12 de septiembre. 